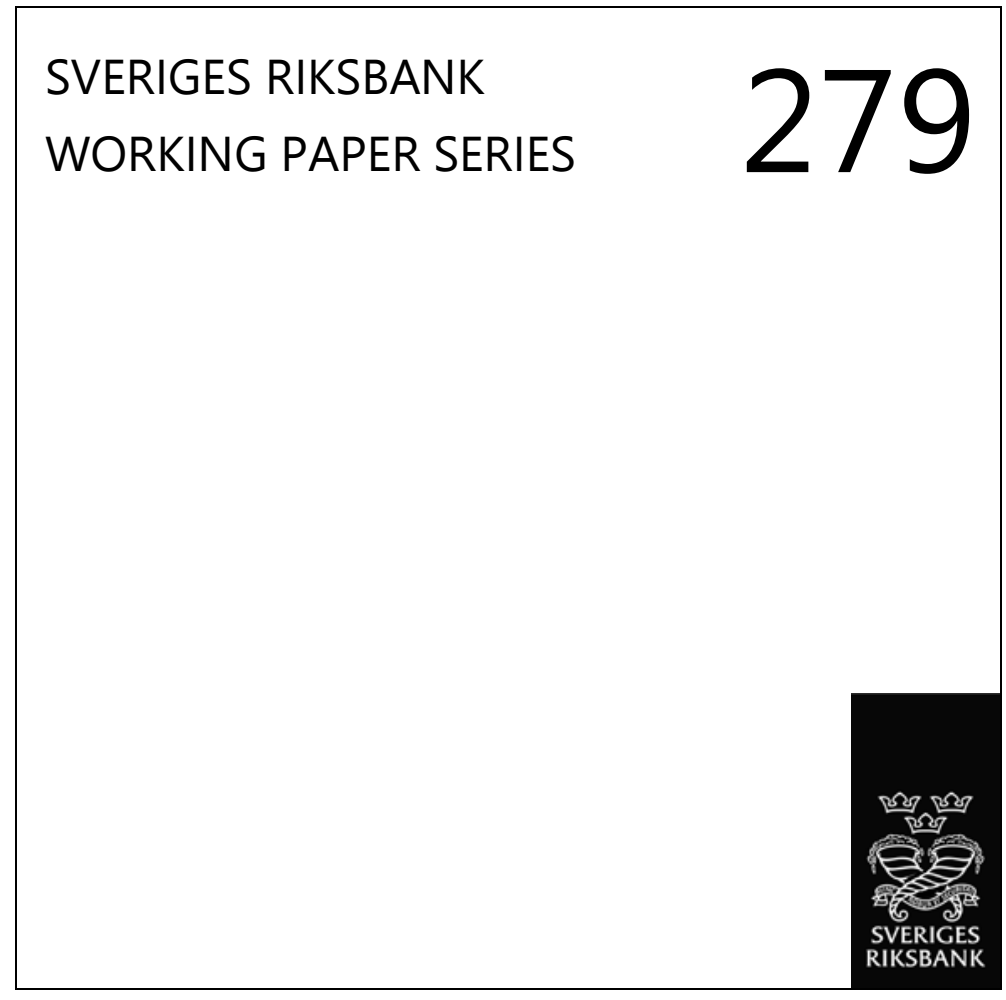

Predicting the Spread of Financial Innovations: An Epidemiological Approach

Isaiah Hull

October 2013 


\section{WORKING PAPERS ARE OBTAINABLE FROM}

Sveriges Riksbank • Information Riksbank • SE-103 37 Stockholm

Fax international: +4687870526

Telephone international: +4687870100

E-mail: info@riksbank.se

The Working Paper series presents reports on matters in the sphere of activities of the Riksbank that are considered to be of interest to a wider public.

The papers are to be regarded as reports on ongoing studies and the authors will be pleased to receive comments.

The views expressed in Working Papers are solely the responsibility of the authors and should not to be interpreted as reflecting the views of the Executive Board of Sveriges Riksbank. 


\title{
Predicting the Spread of Financial Innovations: An Epidemiological Approach
}

\author{
Isaiah Hull ${ }^{\dagger}$ \\ Sveriges Riksbank Working Paper Series \\ No. 279
}

October 2013

I construct an estimable statistic that predicts whether a financial innovation will spread. The approach embeds the multi-host SIR model from epidemiology within a financial model of correlated securities trade; and takes advantage of the related predictive tools from mathematical epidemiology, including the basic reproductive ratio $\left(\mathbb{R}_{0}\right)$ and herd immunity. In the model, banks and their creditors are assumed to have imperfect information about a newly-created security, and must search over the portfolios of other investors and intermediaries to infer the security's properties. In the absence of historical returns data, a large mass of firms holding the new security and not experiencing insolvency provides a positive signal about the distribution of its returns within the current period, and perpetuates further holding of the security. The model yields a set of structural equations that are used to construct the statistic. I provide two estimation strategies for the statistic; and identify 12 theoretical parameter restrictions that enable inference when only a subset of the model's parameters are identifiable. I use the approach to predict the spread of exchange traded funds (ETFs) and asset-backed securities (ABS). Additionally, I show how regulators can use the method to monitor the joint solvency of depository institutions within a given geographic region.

Keywords: Econometric Modeling, Econometric Forecasting, Financial Econometrics, Financial Innovation

JEL Classification: C510, C530, G140, G120

The views expressed in this paper are solely the responsibility of the author and should not be interpreted as reflecting the views of the Executive Board of Sveriges Riksbank.

${ }^{\dagger}$ Research Division, Sveriges Riksbank, SE-103 37, Stockholm, Sweden. Email: isaiah.hull@riksbank.se. 


\section{Introduction}

When a new product is introduced to financial markets, individual and institutional investors do not have access to a historical series of returns from which they can infer the properties of that security. Instead, they must rely on the analysis of ratings agencies and on the information revealed through the decisions of the individual and institutional investors holding it. This cross-section of information about institutional and individual holdings is often incomplete; and will only slowly be revealed through a search process, since centralized information about such a security will usually emerge with a long lag. Thus, investors and institutions must make a decision about whether or not to hold (or issue) the security while information remains imperfect.

The 2007-2010 financial crisis provides a clear example of this process. In the years preceding it, a broad set of financial innovations were introduced and spread throughout the financial system. Commercial banks offered new mortgage products to less creditworthy households; investment banks followed by constructing derivative products from these mortgages; and insurance companies enabled the expansion of these activities by underwriting new contracts for the derivative products. Although no historical information was available about the performance of such financial innovations, institutions began to trade them, basing decisions primarily on the judgement of ratings agencies and on the observation that early adopters were achieving higher returns for a given risk-rating. While these innovations offered what appeared to be improvements in efficiency (i.e. the completion of markets along some dimension), they introduced fragilities into the financial system that were only exposed after a large, negative shock to house prices. If the adoption of such financial innovations had been slower or if the shock had arrived before they became influential within the financial system, it is not clear that the crisis would have been severe and systemic.

Regulators often struggle to prevent such crises because it is difficult to predict which financial products will become systemically important. Thus, mortgage-backed securities, credit default swaps, and the next innovation may fully infiltrate the financial system before a regulator identifies it as important. In light of the 2007-2010 financial crisis, Spence (2008) and others have argued that an "early warning system" is needed to identify risks to the financial system. In this paper, I propose such a system: an estimable statistic that can be used to monitor a wide range of financial securities inexpensively 
and determine whether they are likely to become systemically influential or influential within their class of assets.

The model I propose is based on more than 100 years of work on early warning systems for epidemics; and integrates fairly recent work in mathematical epidemiology. The system revolves around the use of a statistic that is referred to as $\mathbb{R}_{0}$-or the basic reproductive ratio-and the associated concept of herd immunity. In the context of an infectious disease, $\mathbb{R}_{0}$ can be interpreted as the average number of secondary infections that arise from a primary infection. $\mathbb{R}_{0}$ will tend to be high when individuals encounter each other frequently, when the disease is easily transmitted, and when the recovery rate is slow. All of these factors will result in more contacts between "infected" individuals and "susceptible" individuals that result in transmission. Successful transmissions will increase the number of infecteds; and will therefore increase the speed of transmission to the remaining susceptibles.

With respect to epidemiology, estimating $\mathbb{R}_{0}$ for different types of infectious diseases, in different regions, and on the most recent data plays an important part in effective disease control. ${ }^{1}$ A high estimate of $\mathbb{R}_{0}$ in a particular region may suggest that an outbreak will occur if the disease is introduced; and that control measures, such as vaccination or a public health initiative, need to be implemented immediately. Furthermore, $\mathbb{R}_{0}$ is associated with the concept of "herd immunity," which is the set of conditions under which an infectious disease will quickly die out if introduced. This is typically satisfied when $\mathbb{R}_{0}$ is low or when a sufficiently large mass of susceptibles have been vaccinated. In this paper, I will develop both of these concepts in the context of financial innovation; and will demonstrate how each can naturally be mapped to financial data. In addition to introducing $\mathbb{R}_{0}$ and herd immunity as early warning mechanisms for influential financial innovations, I also introduce the class of multi-host epidemiological models-and their associated tools-to economics.

It is important to note that the method developed in this paper will not predict the terminal state of a systemically important financial innovation. Rather, the method will simply predict that an innovation will become important within the financial system or its own asset class, but will not make a distinction between importance driven by a bubble and importance driven by a genuine completion of financial markets. The purpose of this

\footnotetext{
${ }^{1}$ For a recent example, see Mukandavire, Smith, and Morris (2013), who use this approach to analyze the recent Cholera outbreak in Haiti.
} 
approach is to identify potentially influential securities inexpensively, so that regulators can subject them to a greater degree of scrutiny.

This paper will proceed as follows: in the following subsection, I will provide a brief review of the related literature. In Section 2, I will setup a one-host model of financial innovation; and explain its relationship to the SIR and SIS models from epidemiology. I will further describe how $\mathbb{R}_{0}$ and the associated concept of herd immunity are defined in the model. In Section 3, I will construct a model of financial innovation that incorporates the two-host SIR model, where banks and their creditors are the two types of host. In Section 4, I will perform comparative statistics on the version of $\mathbb{R}_{0}$ generated by the model to identify the conditions under which herd immunity is violated when certain parameter values are restricted. In Section 5, I will discuss two methods that can be used to recover $\mathbb{R}_{0}$ and its standard error; and will test the methods by performing three empirical applications. And finally, in Section 6, I will conclude.

\subsection{Related Literature}

This paper is not the first to use a model of infectious disease to describe the flow of information across institutions or investors. Carroll (2003) is perhaps the best known paper that imports work from epidemiology to economics. It uses the common source model to describe the transmission of inflation expectations form professional forecasters to households. It finds that the model accurately captures the dynamics of inflation and unemployment expectations. Several related works, including Sommer and Carroll (2004), and Pfajfar and Santoro (2012) also use epidemiological modeling-rather than rational expectations-to study the way in which households from expectations about inflation. Closer to my own work, Dong, Hong, and Ungureanu (2011) construct a theoretical model in which price-volume dynamics depend explicitly on the diffusion of trader opinions about securities within an epidemiological framework. They show that this approach is useful for understanding the response of investors to news.

Another related literature models the spread of information across investors and institutions, focusing primarily on empirical relationships. Shive (2010) studies social trading using data on the 20 most active stocks in Finland over a period of nine years. She includes in her regression a measure of social contagion that is analogous to a common component of epidemiological models: the interaction of the mass of susceptibles (i.e. the 
fraction of investors not holding the stock) and the mass of infecteds (i.e. the fraction of investors holding the stock). Note that this measure of contagion will be maximized when the mass of susceptibles equals the mass of infecteds. That is, if few people are able to invest in the stock or if few people are currently holding the stock (and, presumably, transmitting information it), then the transmission rate will be low and mass of investors holding it will not rise. Controlling for known determinants of trade, Shive (2010) finds that the coefficient on this term is statistically significant; and plays a substantial role in motivating trade.

Other papers in this literature do not focus explicitly on epidemiological models, but describe similar channels for correlated trade among investors and institutions. Feng and Seasholes (2004), and Hong, Kubik, and Stein (2005) document the role that geography plays in influencing the portfolios that individual and institutional investors hold. Additionally, Antweiler and Frank (2004) find that discussion on Internet stock message boards can predict market volatility, suggesting that social interaction may generate correlated trade. Other papers, including Shiller, Fischer, and Friedman (1984), Hong, Kubik, and Stein (2004), and Ivkovic and Weisbrenner (2007), and Shiller and Pound (1989) also document the influence of social interaction on trade.

Finally, two papers motivate the theoretical treatment of financial innovations in my model. First, Kaustia and Knupfer (2012) study the peer-influenced adoption of financial innovations. They find that individuals who experience positive stock returns will propagate information about those returns to local peers, who then purchase the stock. This corresponds to the "susceptible" investors (i.e. investors who have not held a financial innovation yet) in the model in this paper, who become "infected" (i.e. hold the innovation) after encountering another infected. Persons and Warther (1997) provide further motivation for this approach. In their model, financial innovation is a process through which the value of a security is only realized after it is adopted and returns are generated. Similarly, in the model in this paper, a financial innovation's value is revealed through realizations from the returns distribution. 


\section{A One-Host Model of Financial Innovation}

It will be instructive to briefly describe the SIR model, and its close relative, the SIS model before I describe the model of financial innovation. The name of the model (SIR) refers to the three states an individual may enter over the course of an infectious disease: susceptible, infected, and recovered (SIR). Individuals in the first category (S) do not have the disease, but may contract it after encountering an infected person. Individuals in the second category (I) are currently infected by the disease; and may spread it to susceptibles upon contact. Individuals in the third category $(R)$ have recovered from the disease, rendering them immune. In contrast to the SIR model, the SIS model is used when individuals do not gain immunity, but instead return to the susceptibles group after recovery.

The SIR and SIS model provide several useful tools for analyzing the spread of financial innovations. First, they are designed to predict convergence to one of two types of equilibria after a disease has been introduced: a "disease free equilibrium" (DFE) and an "endemic equilibrium" (EE), which will be discussed in greater detail later. Second, they offer useful predictive tools that map to the data. For our purposes, we will focus on two of these tools: $\mathbb{R}_{0}$ and herd immunity, which will be identical for the SIR and SIS models. And finally, they are flexible enough to permit a wide variety of interactions between different categories of agents in a model; and, thus, may have useful modeling applications within economics, but outside of the scope of this paper.

Moving forward, we will retain the tools and naming conventions of the SIR model, but will work within a financial context. I will start by constructing a simple model of financial innovation that follows the basic structure of the one-host SIR model from epidemiology. I will consider a conceptual setting that is similar to Anjan (2012), where there is only is only one conventional security is available initially. There is a continuum of banks, and each initially has an endowment, D, of debt-financed funds (i.e. deposits, commercial paper, etc.) and capital, $\tau D$. The capital must be retained in order to avoid intervention from the regulator. Initially, the debt-financed funds are invested in the conventional security initially. The unconventional asset is introduced when a random financial institution innovates by creating the security. Other institutions only also create the security after they have discovered its existence. This new security generates a stochastic return, $b(t, i)$, that is drawn from a common, time-varying distribution: 


$$
F(\bar{b} ; t)=\operatorname{pr}\{b(t, i) \leq \bar{b}\}
$$

I will assume that $\mathrm{F}$ has a finite support, but will permit the bounds to vary over time in the most general case:

$$
b(t, i) \in\left[b^{L}(t), b^{H}(t)\right]
$$

No further assumptions will be imposed on F. Additionally, note that everything we have assumed so far is intuitively plausible and unrestrictive. Even in the most extreme cases, a bank cannot lose more than it invested (i.e. $b^{L}(t) \geq 0$ ) and cannot receive an infinite return (i.e. $\left.b^{H}(t)<\infty\right)$.

Once the unconventional asset is introduced, it is assumed that non-innovating banks will encounter it through a search process. In each period, a bank searches over the portfolios of $\mathrm{q}$ other random banks. If one bank encounters another with the unconventional asset during a search, it will believe that the security provides a fundamental improvement over the conventional options (and will adopt it) with probability c. Thus, the joint probability of encountering and adopting an unconventional asset is given by $\beta=q c$. Note that this specification reproduces the effect in Gale (1992): if finding and adopting the unconventional security is a long and costly process (i.e. q is very low), then the unconventional security will not spread and the conventional security will become the standard asset (as we will see later in this section).

It will further be assumed that some mass of financial intermediaries, g, enters the market in each period; and some other mass of firms, e, exits the model for reasons unrelated to he unconventional security. We will assume that $\mathrm{g}=\mathrm{e}$ or $\mathrm{g}=\mathrm{e}=0$ for sufficiently small time horizons to simplify he model. It will further be assumed that a firm will stop holding the unconventional security permanently if it performs worse than the conventional security.

With the above assumptions in place, we may now write down the three flow equations that characterize a typical SIR model. The first equation describes the net flow of banks into the category of "conventional asset holder." I will retain the notation of the SIR model and denote the mass of these institutions as $\mathrm{S}$ (i.e. susceptible). Here, the term "susceptible" indicates that a bank is not currently holding the financial innovation, but may adopt it if encountered on a search: 


$$
\frac{\partial S}{\partial t}=g-\beta S I-e S
$$

This equation states that the net flow into the conventional security group is given by the net mass of entries less the mass of banks that switch to the unconventional asset. There are several things to note about the above specification. First, the net entries component of the equation relies on the assumption that all entering firms initially hold only the conventional asset. This is why the conventional asset holding group grows by g, rather than $e S$. And second, the population is assumed to be well-mixed: it is just as likely that firm A will search firm B's portfolio as it is that firm A will search firm C's portfolio. By the Law of Large Numbers (LLN), the mass of banks holding conventional assets that will encounter banks holding unconventional asset is given by $S I$ for a single round of searches. Furthermore, the mass of banks that will switch from the conventional asset to the unconventional asset is the total number of encounters per search, multiplied by the number of searches, multiplied by the conditional probability of switching, given an encounter: $\beta I S$.

Next, we consider the equation for the flow of unconventional security holding banks, whose mass we denote with I:

$$
\frac{\partial I}{\partial t}=\beta S I-(\gamma+m+e) I
$$

The first term, $\beta S I$, is the mass of banks flowing out of the conventional securities group that have opted to hold the unconventional asset. The second term, $(\gamma+m+e) I$ describes the flow out of the unconventional asset group, which can be caused by three different events. First, a bank may exit the industry for reasons unrelated to the unconventional asset, e. Second, exit may be forced by government intervention if a bank violates the capital holding requirement. This will occur with probability $m$ and is triggered when an institution holds the unconventional asset and realizes a loss that exceeds $\tau D$. Finally, if a bank realizes a return that is lower than what can be obtained from the conventional asset, then the institution will permanently switch from the unconventional asset back to the conventional asset. This occurs with probability $\gamma .^{2}$

Finally, we write down the flow equation for the group that experienced a loss from the

\footnotetext{
${ }^{2}$ In the SIR model, this switch is permanent. In the SIS model, it is temporary.
} 
unconventional asset and switched back to the conventional asset. Using the convention from the SIR model, we will use R to denote this "recovered" group's mass:

$$
\frac{\partial R}{\partial t}=\gamma I-e R
$$

The above equation states that the net mass of banks "recovering" from the unconventional asset is given by the difference between, $\gamma I$, the mass of banks making a permanent switch from the unconventional security to the conventional security, and $e R$, the mass of banks exiting the model from the recovered category.

Finally, we will specify the functional forms for $m$ and $\gamma$, which come directly from the model. We will start with $m$, which is the probability that an institution experiences a loss that exceeds their required conventional asset holdings. This can alternatively be interpreted as the probability that an institution will not be able to repay its debtors, even after it exhausts the buffer stock of capital it was required to hold. The condition below states that the loss must exceed the required capital holdings:

$$
\begin{gathered}
m=\operatorname{pr}\{(1-b(t, i)) D>\tau D\} \\
\rightarrow m=\operatorname{pr}\{(1-\tau)>b(t, i)\} \\
\rightarrow m=F(1-\tau ; t)
\end{gathered}
$$

Consistent with intuition, this specification for $m$ implies that the bank failure rate is decreasing in the conventional asset-holding regulatory requirement:

$$
\frac{\partial m}{\partial \tau}=-F^{\prime}(1-\tau ; t)
$$

Since $\mathrm{F}$ is a cumulative distribution function, $-F^{\prime}$ will always be negative. Next, we consider the specification for $\gamma$, which is also implied by the model. The expression for $\gamma$ gives us the probability that an institution will have a sufficient buffer stock of safe assets to repay debtors, but that the repayment process will cause them to violate the capital holding requirement. This is given by the probability of a loss, less the probability of a 
loss that is larger than the buffer stock of capital:

$$
\begin{gathered}
\gamma=F(1 ; t)-m_{t} \\
\rightarrow \gamma=F(1 ; t)-F(1-\tau ; t)
\end{gathered}
$$

Note that the construction of $\gamma$ implies that the bank recovery rate is increasing in $\tau$ :

$$
\frac{\partial \gamma}{\partial \tau}=F^{\prime}(1-\tau ; t)>0
$$

That is, an increase in capital holdings will increase the rate at which financial institutions switch back to the conventional asset permanently. This is because a higher value of $\tau$ will prevent banks from exhausting all capital after realizing a very unfavorable return. As will be shown later, a high regulatory requirement to hold safe assets will tend to prevent unconventional assets from gaining share within their asset class.

Note that we can now rewrite the net flow equation for unconventional security holders ("infecteds"):

$$
\frac{\partial I}{\partial t}=\beta S I-(F(1 ; t)+e) I
$$

We will now consider the threshold at which the unconventional asset ceases to grow as a share of its asset class. In particular, the mass of unconventional asset holding banks must remain constant. To simplify things further, we will assume that the returns distribution for the unconventional security, F, is fixed over some short time horizon, which enables us to treat $\gamma$ and $m$ as constants. We may think of this as an initial stable period of returns after an innovation has been introduced and no adverse shocks have been realized.

$$
\begin{gathered}
0=\frac{\partial I}{\partial t}=\beta S I-(\gamma+m+e) I \\
\rightarrow \frac{1}{S}=\frac{\beta}{\gamma+m+e}
\end{gathered}
$$

In the epidemiology literature, the right hand side of this threshold condition is referred to as $\mathbb{R}_{0}$ or the basic reproductive number (BRN). This statistic provides us with the ratio of the entry rate to the exit rate in the unconventional securities group. In this context, $\mathbb{R}_{0}$ can be interpreted as the average number of conventional asset holding banks that are 
converted to unconventional asset holders when one bank adopts the unconventional asset. Note that high values of $\gamma, \mathrm{m}$, and e will lower $\mathbb{R}_{0}$ by reducing the pool of unconventional asset holders, subsequently making it more difficult for conventional asset holders to encounter the financial innovation. Similarly, if the search process is slow or costly (i.e. if q is low) or if a particular financial innovation does not appear to be a credible improvement over what is already available (i.e. if $\mathrm{c}$ is low), then $\mathbb{R}_{0}$ will tend to be low.

Next, we will characterize the existence and stability of equilibria in the model. In particular, the one-host class of SIR models has two types of equilibria: an "endemic" equilibrium (EE) and a "disease free" equilibrium (DFE). In a DFE, the infectious disease has disappeared and all recovereds have exited the model, leaving the entire population to accumulate in the "susceptibles" category. In the EE, the disease persists in the population.

We start by noting that an equilibrium is defined by the absence of movement across categories:

$$
\begin{gathered}
0=e-\beta I^{*} S^{*}-e S^{*} \\
0=\beta I^{*} S^{*}-(\gamma+m+e) I^{*} \\
0=\gamma I^{*}-e R^{*}
\end{gathered}
$$

In the above equations, the superscript $*$ indicates a steady state value. Note that equation (17) can be factored as follows:

$$
0=I^{*}\left(\beta S^{*}-(\gamma+m+e)\right)
$$

This has two solutions: $I^{*}=0$ and $S^{*}=\frac{\gamma+m+e}{\beta}=\frac{1}{\mathbb{R}_{0}}$. The first solution is the DFE, since no agents hold the unconventional asset in the steady state. When we plug $I^{*}=0$ into equation (16), we find that $S^{*}=1$. Since $S+I+R=1$, we know that $R^{*}=0$. Thus, the DFE may be characterized as follows:

$$
\left(S^{*}, I^{*}, R^{*}\right)=(1,0,0)
$$

Next, we consider the second solution to equation (17): $S^{*}=\frac{1}{\mathbb{R}_{0}}$. If we plug this into equation (16), we get that $I^{*}=\frac{e}{\beta}\left(\mathbb{R}_{0}-1\right)$. Finally, solving for $R^{*}$, we find that $R^{*}=$ $\frac{\gamma}{\beta}\left(\mathbb{R}_{0}-1\right)$. This gives us the following EE: 


$$
\left(S^{*}, I^{*}, R^{*}\right)=\left(\frac{1}{\mathbb{R}_{0}}, \frac{e}{\beta}\left(\mathbb{R}_{0}-1\right), \frac{\gamma}{\beta}\left(\mathbb{R}_{0}-1\right)\right)
$$

A well-known result in the epidemiology literature is that the EE is stable if $\mathbb{R}_{0}>1$ and the DFE is stable otherwise. ${ }^{3}$ In our case, this suggests that, if $\mathbb{R}_{0}>1$, and a small amount of the unconventional asset is introduced, then we will move to the endemic equilibrium, where the unconventional asset grows in importance and remains in use in the steady state.

In the case where there is no recovered group (the SIS model), $\mathbb{R}_{0}$ will be identical, since equation (4) is unchanged; however, the size of the susceptible group in in the EE will decline:

$$
\left(S^{*}, I^{*}\right)=\left(\frac{1}{\mathbb{R}_{0}}, \frac{\left(\mathbb{R}_{0}-1\right)}{\beta-\gamma \mathbb{R}_{0}}\right)
$$

In general, "herd immunity" is said to hold if the system returns to the DFE after a shock introduces some mass of the unconventional asset. If, instead, the system moves towards an EE, then herd immunity is violated. Within epidemiology, herd immunity is achieved by immunizing a fraction of the population of susceptibles, $\mathrm{P}$, and thereby reducing the number of interactions that can result in infection. Here, it is also possible to achieve herd immunity by changing $\mathbb{R}_{0}$ through a regulatory intervention.

Figures I and II show the SIS model's dynamics for two cases: 1) $\mathbb{R}_{0}>1$ (EE) and 2) $\mathbb{R}_{0}<1$ (DFE), respectively. In Figure I, a large shock introduces the innovation to $20 \%$ of banks, but it quickly disappears, as the system returns to the DFE. In Figure II, a random shock introduces the financial innovation to $1 \%$ of banks. It then spreads quickly to susceptible banks, moving the system towards the EE.

One important thing to note is that $\mathbb{R}_{0}$ may vary over time in either the SIR or SIS model:

$$
\mathbb{R}_{0}=\frac{\beta}{\gamma+m+e}=\frac{\beta}{F(1 ; t)+e}
$$

In particular, consider the case where the estimate of $\mathbb{R}_{0}$ is less than 1 initially. Using the method outlined above, we would predict that the unconventional asset will not become systemically important or important within its asset class. However, if we have a reason

\footnotetext{
${ }^{3}$ This can be demonstrated by constructing the Jacobian and checking the eigenvalues. See Keeling and Rohani (2008) for a short proof.
} 

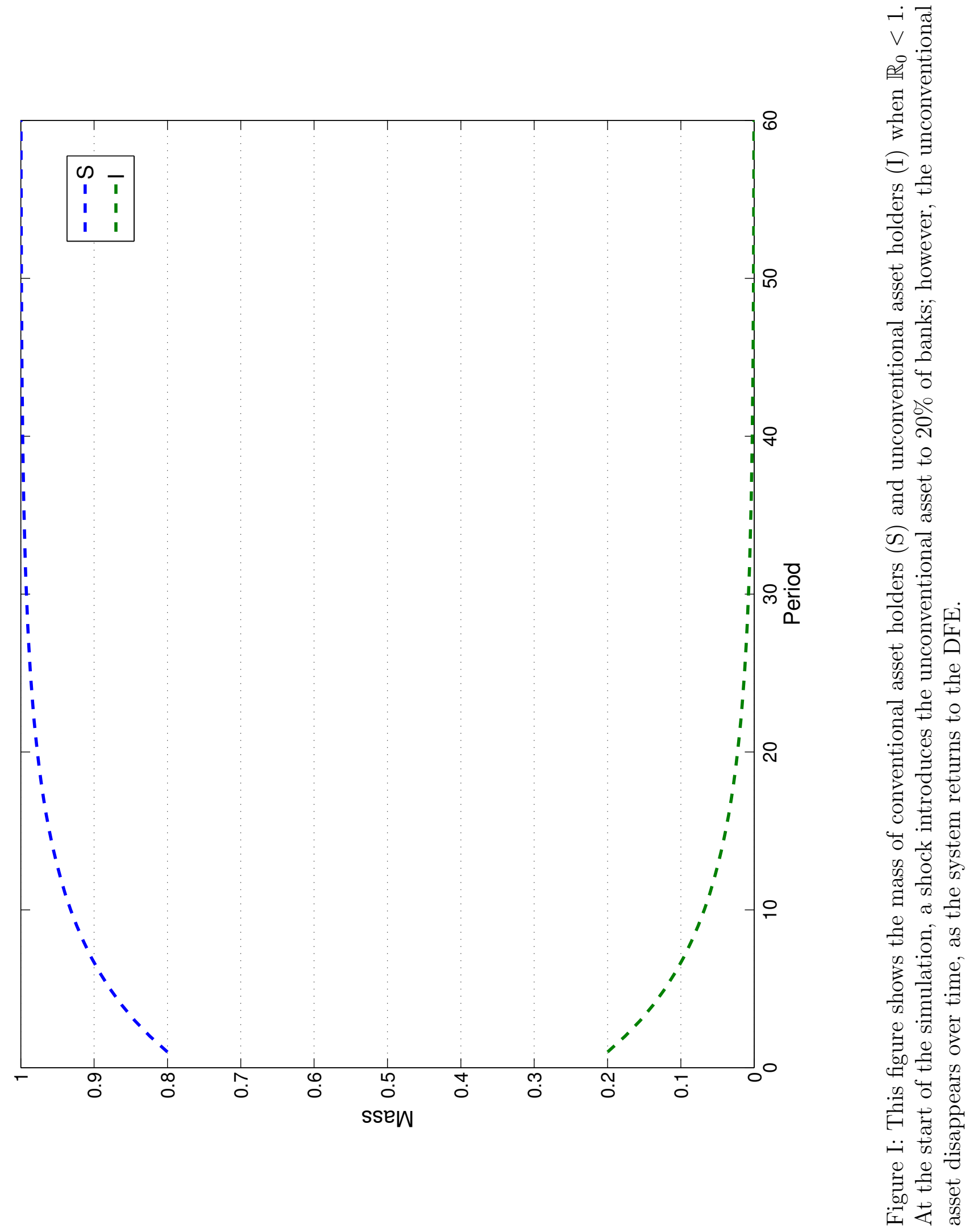


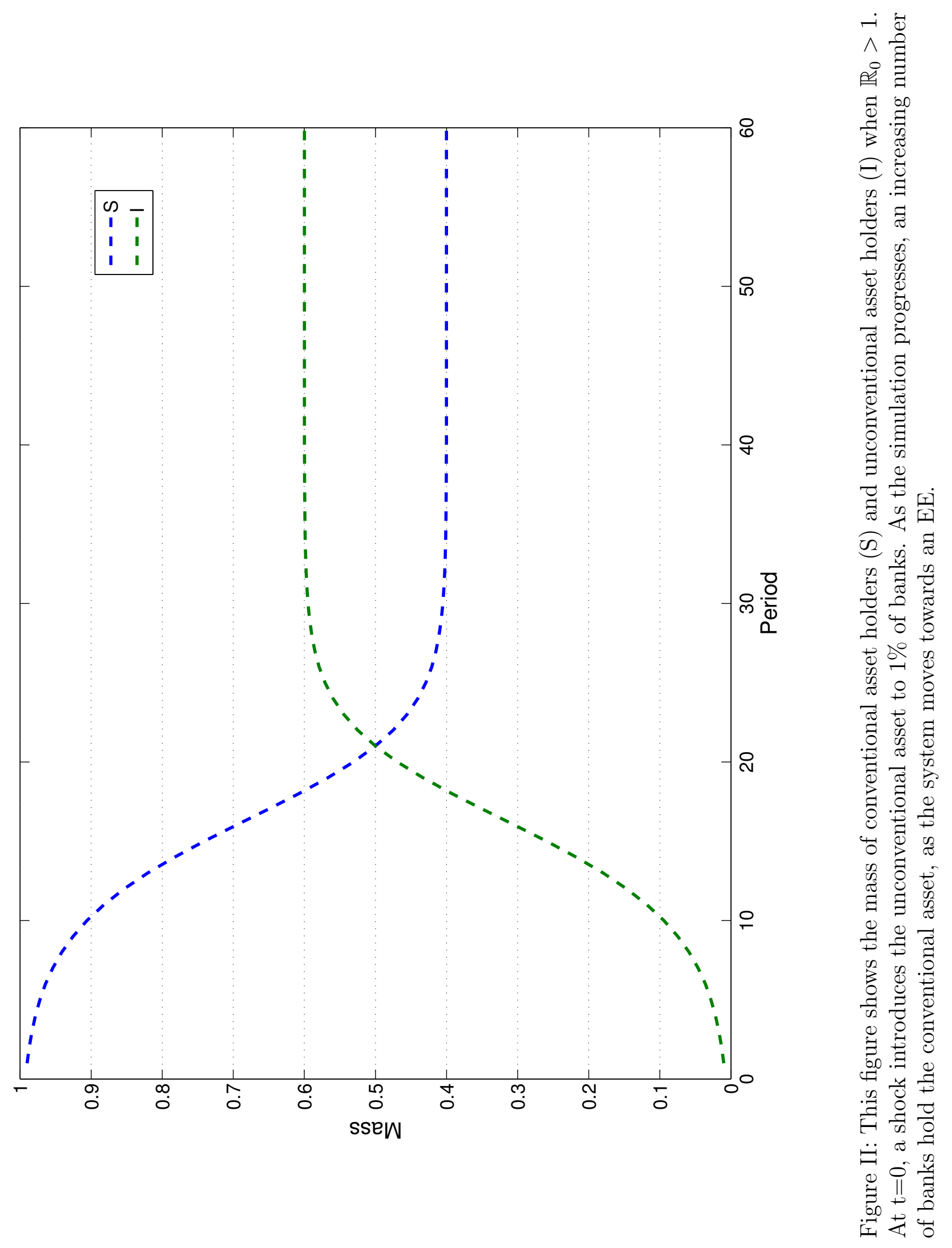


to believe that losses will become less likely in the near future, then $F(1 ; t)$ will fall, increasing $\mathbb{R}_{0}$ and possibly propelling financial markets toward an endemic equilibria, where the unconventional asset becomes influential and is held in the steady state.

\section{A Two-Host SIR Model of Financial Epidemics}

I will now construct a general framework for financial innovation using a 2-host version of the SIR model. From this, I will show how $\mathbb{R}_{0}$ is derived for the 2-host version-and, relatedly, will demonstrate the conditions under which herd immunity holds. Finally, I will explain how to construct the basic reproductive number for the general multi-host case. All of this will be done through the framework in McCormack (2007). To this author's knowledge, this has not yet been done in economics.

The model describes the interactions between two categories of financial agents: banks (B) and their creditors (C). ${ }^{4}$ Banks play two roles in the model: first, they generate funding through debt (e.g. by accepting deposits, issuing commercial paper, etc.); and second, they use the funds generated to purchase securities, which may be either conventional or unconventional. Creditors enter the model with an endowment of cash, D, which they initially place in a random bank. All banks invest exclusively in a conventional asset at the start of the model; and this asset generates a normalized return of 1 with certainty. As with the one-host version, the unconventional asset is introduced at a random bank as a financial innovation; and generates a return that is drawn from a common, time-varying distribution with properties identical to the ones described in the previous section. Banks are assumed to generate zero profits. As with the one-host case, banks are endowed with $\tau D$ in capital; and are required by the regulator to maintain these holdings.

The transmission mechanism for the unconventional asset (after it is introduced) is similar to the one-host case, but with more sources. Banks, for example, may still encounter the unconventional asset by searching the portfolios of other banks. As with the one-host case, the product of the conditional probability of unconventional asset adoption and the frequency of search yields the interbank transmission rate, $\beta_{B, B}$. Notice that the subscripting convention $(\mathrm{B}, \mathrm{B})$ indicates that the transmission is from a bank and to a

\footnotetext{
${ }^{4}$ Here, I use "bank" and "creditor" to describe the model's categories of agent, but the terms are used loosely. In the applications I will describe later, the creditor category may refer to a wide variety of individuals and institutions, including depositors and commercial paper buyers. Similarly, the term bank refers to non-depository institutions in some applications.
} 
bank. In addition to this, banks will now also be persuaded to hold the unconventional asset by interactions with prospective creditors. Creditors who currently hold accounts at banks with unconventional assets will continue to search for better returns. In the process, they will encounter banks holding conventional assets. With some probability, the bank will learn about the value of the unconventional asset when it is rejected by a creditor who already has access to it. The product of the frequency of interactions with creditors and the conditional probability of unconventional asset adoption (given an interaction with a creditor) is embodied by the creditor-to-bank transmission rate: $\beta_{C, B}$. As in the one-host model, I assume perfect mixing within the banking sector. Here, I extend that assumption to the group of creditors and across bank-creditor relationships. Additionally, I assume that banks enter the industry in the conventional category at a fixed rate; and also exit the industry from all categories at a fixed rate for reasons unrelated to the unconventional asset. Together, these assumptions yield the first of six equations that characterize the model:

$$
\frac{\partial S_{B}}{\partial t}=g_{B}-\beta_{B, B} I_{B} S_{B}-\beta_{C, B} I_{C} S_{B}-e_{B} S_{B}
$$

Note that $e_{B}$ is the growth rate of banks and $e_{B}$ is the mortality rate for reasons other than exposure to the infectious disease.

The next equation describes the net flow of creditors into banks that hold the conventional asset. Here, it is assumed that creditors may be persuaded to switch to an unconventional asset holding bank after encountering either an unconventional asset holding bank $\left(\beta_{B, C}\right)$ or an unconventional asset holding creditor $\left(\beta_{C, C}\right)$ :

$$
\frac{\partial S_{C}}{\partial t}=g_{D}-\beta_{C, C} I_{C} S_{C}-\beta_{B, C} I_{B} S_{C}-e_{B} S_{C}
$$

The next two equations describe the net flow of banks and creditors into the unconventional asset holding category. We know from the first two equations that there will be an inflow from the conventional asset holding category. Additionally, there will be an outflow that is similar to the one described in the one-host version of the model. For banks, this consists of institutions that realize a loss on unconventional assets, including losses that exceed capital holdings, $\gamma_{B}$, and those that do not, $m_{B}$. Creditors are assumed to switch back to the conventional asset after realizing a loss. This will occur whenever 
their debtor bank realizes a loss that exceeds its capital holdings (i.e. at rate $\gamma_{C}$ ). It is also assumed that creditors may be bankrupted by a loss; however, the boundedness of losses and the regulatory requirements will result in $m_{C}=0$.

$$
\begin{aligned}
\frac{\partial I_{B}}{\partial t} & =\beta_{B, B} I_{B} S_{B}-\beta_{C, B} I_{C} S_{B}-\left(\gamma_{B}+m_{B}+e_{B}\right) I_{B} \\
\frac{\partial I_{C}}{\partial t} & =\beta_{C, C} I_{C} S_{C}-\beta_{B, C} I_{B} S_{C}-\left(\gamma_{C}+m_{C}+e_{C}\right) I_{C}
\end{aligned}
$$

Finally, the equations that describe the net flow of banks and creditors into the recovered category are given below:

$$
\begin{aligned}
& \frac{\partial R_{B}}{\partial t}=\gamma_{B} I_{B}-e_{B} R_{B} \\
& \frac{\partial R_{C}}{\partial t}=\gamma_{C} I_{C}-e_{C} R_{C}
\end{aligned}
$$

Note that the first component of the net flow is the inflow from the unconventional asset holding category. The outflow consists of banks and creditors exiting the industry for reasons unrelated to the unconventional asset. Alternatively, in the SIS case, the inflow is redirected to the susceptibles category.

Figure III shows the basic structure of the model described in this section. Individuals in each group may move from susceptible (conventional asset-holding) to infected (unconventional) and from infected to recovered (permanently conventional), as indicated by the solid arrows. Dotted arrows indicate that the mass of the unconventional asset group impacts the flows of individuals between groups. In particular, as the mass of unconventional asset holding banks grow, conventional asset holding banks and creditors at conventional asset holding banks become more likely to encounter unconventional asset holding banks. As a result, the flows of banks and creditors from the conventional to the unconventional category increase.

I have now specified the full, six-equation version of the model. Next, I will derive $\gamma_{C}, \gamma_{B}, m_{C}$, and $m_{B}$. I will start with the unconventional asset-induced exit rates, $m_{B}$ and $m_{C}$. From the model, we know that all investors start at $\mathrm{t}=0$ with $D$ units of currency, which are immediately deposited in a random, conventional asset holding bank. Furthermore, banks are assumed to have an endowment, $\tau D$, of capital, which the regulator requires them to hold. Applying the Law of Large Numbers (LLN) yields the 

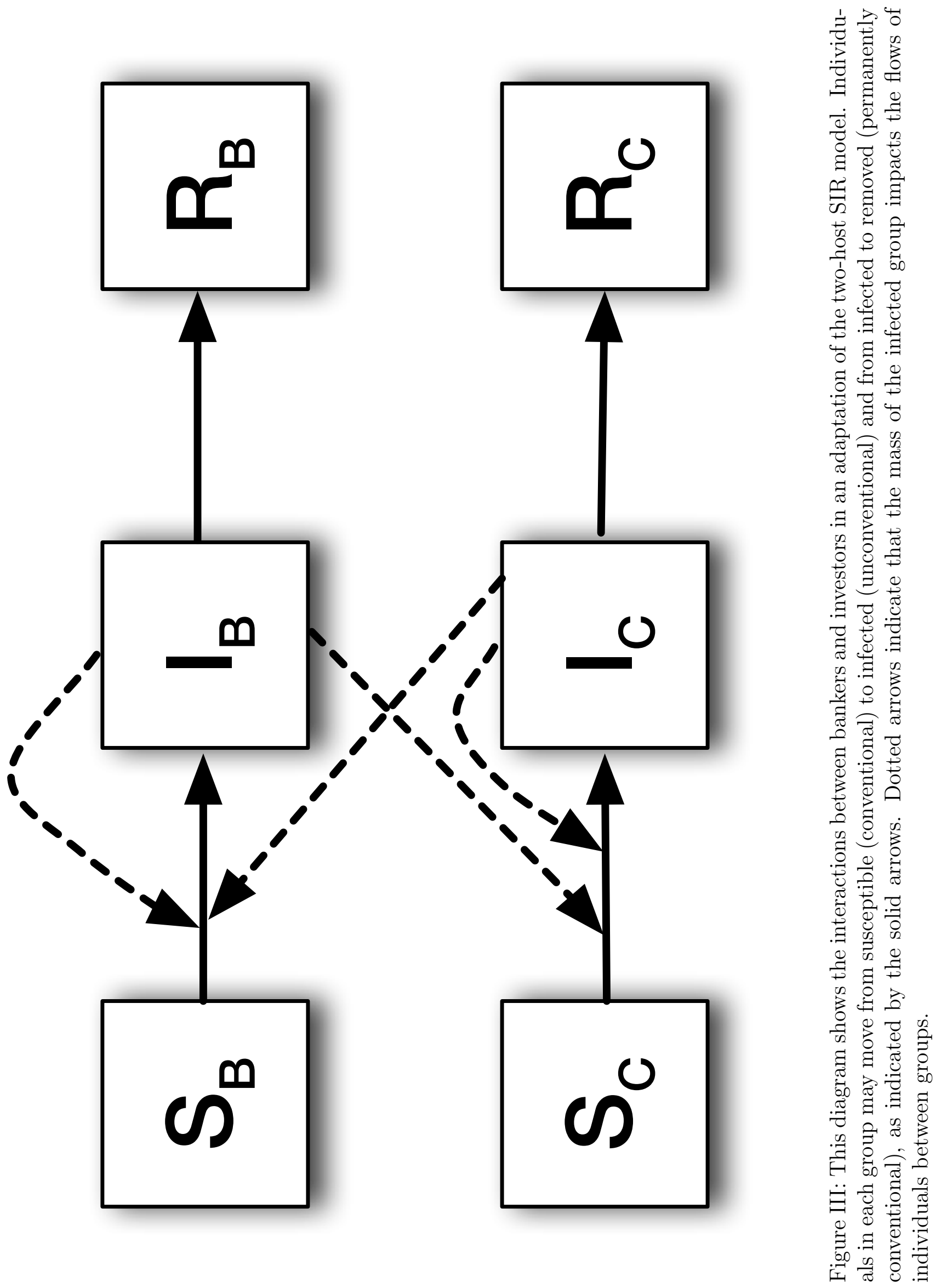
following bankruptcy rate:

$$
\begin{gathered}
m_{B}=\operatorname{pr}\left\{(1-b(t)) I_{C} D>\tau I_{B} D\right\}=\operatorname{pr}\left\{1-b(t)>\tau I_{B} / I_{C}\right\} \\
=\operatorname{pr}\left\{b(t)<\left(I_{C}-\tau I_{B}\right) / I_{C}\right\} \\
=F\left(\left(I_{C}-\tau I_{B}\right) / I_{C} ; t\right)
\end{gathered}
$$

The interpretation of equation (30) is simple: if an intermediary invests in an unconventional asset, and that asset generates a return lower than the principal invested, then the bank will have to use its capital to repay investors. If the capital is not sufficient to repay principal, then the bank will exit after dividing all remaining funds among creditors. ${ }^{5}$

As with the one-host model, the unconventional asset-induced exit rate is decreasing in $\tau$, the required fraction of capital holdings; however, in the two-host version of the model, it also depends explicitly on the mass of creditors in the unconventional asset holding banks and the mass of unconventional asset holding banks:

$$
\frac{\partial m_{B}}{\partial \tau}=-\frac{I_{B}}{I_{C}} F^{\prime}\left(\left(I_{C}-\tau I_{B}\right) / I_{C} ; t\right)<0
$$

Similarly, notice that the bankruptcy rate is increasing in $I_{C}$ and decreasing in $I_{B}$ :

$$
\begin{aligned}
\frac{\partial m_{B}}{\partial I_{C}} & =\frac{\tau I_{B}}{\left(I_{C}\right)^{2}} F^{\prime}\left(\left(I_{C}-\tau I_{B}\right) / I_{C} ; t\right)>0 \\
\frac{\partial m_{B}}{\partial I_{B}} & =-\frac{\tau}{I_{C}} F^{\prime}\left(\left(I_{C}-\tau I_{B}\right) / I_{C} ; t\right)<0
\end{aligned}
$$

One feature of this setup is that bankruptcy rates depend on bank leverage. As the mass of creditors lending to unconventional asset banks grows relative to the capital holdings in these institutions (i.e. as a rough measure of leverage increases), the bankruptcy rate accelerates.

I will now place structure on the rate at which unconventional asset banks switch back to purchasing conventional assets. I assume that this happens when such a bank experiences a loss that reduces its capital holdings, but that loss isn't sufficiently large to trigger bankruptcy. As a result of the intermediary losing some of its initial capital hold-

\footnotetext{
${ }^{5}$ Of course, this is a strong condition for bankruptcy. Bank may often choose to initiate a strategic bankruptcy, even if their capital holdings are not completely depleted; however, I will maintain this assumption in the model for tractability.
} 
ings, it will choose not to continue purchasing unconventional assets ${ }^{6}$-and instead dump remaining principal in conventional assets.

Next, the recovery rate for the bank is computed. Two conditions must be satisfied in order for a bank to move from the conventional (S) to unconventional (I) asset holding group: 1) the bank must experience a loss-that is, $b(t, i)<1$; and 2) the loss must be smaller than the amount of capital the bank holds: $(1-b(t, i)) D I_{C}<\tau D I_{B}$. Again, taking advantage of the LLN and the within period distributional assumptions, we get the following:

$$
\begin{gathered}
\gamma_{B}=F(1 ; t)-m_{B} \\
\rightarrow \gamma_{B}=F(1 ; t)-F\left(\left(I_{C}-\tau I_{B}\right) / I_{C} ; t\right)
\end{gathered}
$$

Notice that the recovery rate for banks is increasing in $\tau$ :

$$
\frac{\partial \gamma_{B}}{\partial \tau}=\frac{I_{B}}{I_{C}} F^{\prime}\left(\left(I_{C}-\tau I_{B}\right) / I_{C} ; t\right)>0
$$

This is because more banks will recover-rather than exit-after realizing a large, negative shock. Furthermore, notice that $\frac{\partial \gamma_{B}}{\partial \tau}+\frac{\partial m_{B}}{\partial \tau}+\frac{\partial e}{\partial \tau}=0$. Thus, an increase in required capital holdings will have no impact on the rate at which banks flow out of the unconventional asset holder category. Instead, it will affect the composition of the outflow.

Similarly, notice that the recovery rate is increasing in $I_{C}$ and decreasing in $I_{B}$ :

$$
\begin{gathered}
\frac{\partial \gamma_{B}}{\partial I_{C}}=-\frac{I_{B}}{\left(I_{C}\right)^{2}} F^{\prime}\left(\left(I_{C}-\tau I_{B}\right) / I_{C} ; t\right)>0 \\
\frac{\partial \gamma_{B}}{\partial I_{B}}=\frac{\tau}{I_{C}} F^{\prime}\left(\left(I_{C}-\tau I_{B}\right) / I_{C} ; t\right)<0
\end{gathered}
$$

Finally, the rate at which creditors switch from unconventional assets to conventional assets (i.e. the creditor recovery rate) is computed. Recall that a bank will repay principal until it has exhausted all of its capital. This means that an investor will not incur a loss unless the financial institution exits the model. Thus, the fraction of investors who hold unconventional assets and then "recover," switching back to conventional assets permanently, is equal to the fraction that becomes bankrupt. Recall that this was computed earlier as the unconventional asset-induced exit rate for banks:

\footnotetext{
${ }^{6}$ Note that this "recovery" could be temporary-or it could allow them to issue conventional assets again with the possibility of moving back to unconventional ones.
} 


$$
\gamma_{C}=F\left(\left(I_{C t}-\tau I_{B}\right) / I_{C t} ; t\right)
$$

Taken together, equations (24)-(29), (32), (36), (38), and (41) specify a complete, twohost SIR model of financial bubbles. Next, I will compute the basic reproduction number (BRN) for the two-host case.

Following McCormack (2007), $\mathbb{R}_{0}$ (the BRN) can be computed from the spectral radius of the $n x n$ matrix, $M_{n}$, where $M_{n}=\left(\mathbb{R}_{j, k}\right)_{j, k=1}^{n}$. Each $\mathbb{R}_{j, k}$ in the matrix is given as follows:

$$
\mathbb{R}_{j, k}=\frac{K_{j} \beta_{j, k}}{K_{k}\left(\gamma_{k}+m_{k}+e_{k}\right)}
$$

Here, $K_{j}$ and $K_{k}$ are the maximum sizes of groups $\mathrm{j}$ and $\mathrm{k}$. In this paper, the populations of bankers and creditors are normalized to 1, so these terms drop out of the equation. However, even without this normalization, the terms will cancel out in the two-host case when $\mathbb{R}_{0}$ is computed.

In the two-host case considered in this paper, the $M_{2}$ matrix is given as follows:

$$
M_{2}=\left(\begin{array}{ll}
\mathbb{R}_{B, B} & \mathbb{R}_{B, C} \\
\mathbb{R}_{C, B} & \mathbb{R}_{C, C}
\end{array}\right)
$$

Thus, the BRN is computed as follows:

$$
\mathbb{R}_{0}=\frac{\mathbb{R}_{B, B}+\mathbb{R}_{C, C}+\sqrt{\left(\mathbb{R}_{B, B}-\mathbb{R}_{C, C}\right)^{2}+4 \mathbb{R}_{B, C} \mathbb{R}_{C, B}}}{2}
$$

Rewriting this expression in terms of the parameters and variables in the two-host model yields the following:

$$
\begin{aligned}
\mathbb{R}_{0}= & \frac{1}{2} \sqrt{\left(\frac{\beta_{B, B}}{\gamma_{B}+m_{B}+e_{B}}-\frac{\beta_{C, C}}{\gamma_{C}+m_{C}+e_{C}}\right)^{2}+\frac{4 \beta_{B, C} \beta_{C, B}}{\left(\gamma_{C}+m_{C}+e_{C}\right)\left(\gamma_{B}+m_{B}+e_{B}\right)}} \\
& +\frac{1}{2}\left(\frac{\beta_{B, B}}{\gamma_{B}+m_{B}+e_{B}}+\frac{\beta_{C, C}}{\gamma_{C}+m_{C}+e_{C}}\right)
\end{aligned}
$$

Finally, we use McCormack (2007) to define the condition for herd immunity without 
explicitly using the mass of conventional asset holding banks or creditors. Here, we exploit the fact that $\mathbb{R}_{0}$ is the average number of unconventional asset transmissions that arise from an initial bank or creditor holding the unconventional asset. This means that the unconventional asset will-become influential, rather than remaining small or disappearing-if the following condition holds:

$$
\mathbb{R}_{0}>1
$$

That is, if each bank (or creditor) that adopts the unconventional asset spreads the unconventional asset to more than one bank (or creditor) on average, then the unconventional asset groups will grow when the financial innovation is introduced, moving the system towards an "endemic equilibrium." Otherwise, the financial innovation will disappear or remain inconsequential. See Diekmann and Heesterbeek (1990), van den Driessche and Watmough (2002), and McCormack (2007) for formal proofs of the existence and stability of the DFE and EE in the two-host case.

\section{Comparative Statics}

Next, we will perform comparative statistics to derive properties that will simplify estimation. We will start by recalling that herd immunity requires the following condition on $\mathbb{R}_{0}$ to hold:

$$
\begin{aligned}
\mathbb{R}_{0}= & \frac{1}{2} \sqrt{\left(\frac{\beta_{B, B}}{\gamma_{B}+m_{B}+e_{B}}-\frac{\beta_{C, C}}{\gamma_{C}+m_{C}+e_{C}}\right)^{2}+\frac{4 \beta_{B, C} \beta_{C, B}}{\left(\gamma_{C}+m_{C}+e_{C}\right)\left(\gamma_{B}+m_{B}+e_{B}\right)}} \\
& +\frac{1}{2}\left(\frac{\beta_{B, B}}{\gamma_{B}+m_{B}+e_{B}}+\frac{\beta_{C, C}}{\gamma_{C}+m_{C}+e_{C}}\right)<1
\end{aligned}
$$

Furthermore, note that herd immunity in this context refers to a state in which the unconventional asset will not spread to the population of banks and creditors (i.e. the system will not move to the EE).

Now, assume that the time horizon under consideration is sufficiently short and exit does not occur on any significant scale: $e_{B}=e_{C}=0$. That is, creditors and banks exit for reasons other than receiving poor returns to the unconventional asset. ${ }^{7}$ Addi-

\footnotetext{
${ }^{7}$ This is certainly not an accurate assumption; however, in more rigorous applications, this rate can be calibrated to match real bankruptcy rates.
} 
tionally, recall that $m_{C}=0$-that is, investors are assumed not to exit as a result of the unconventional asset. The condition on $\mathbb{R}_{0}$ now is now simplified to the following:

$$
2>\sqrt{\left(\frac{\beta_{B, B}}{\gamma_{B}+m_{B}}-\frac{\beta_{C, C}}{\gamma_{C}}\right)^{2}+\frac{4 \beta_{B, C} \beta_{C, B}}{\left(\gamma_{B}+m_{B}\right) \gamma_{C}}}+\left(\frac{\beta_{B, B}}{\gamma_{B}+m_{B}}+\frac{\beta_{C, C}}{\gamma_{C}}\right)
$$

Using parameter restrictions and simple algebraic manipulations, it is now possible to determine the conditions under which markets will be susceptible to the spread of an unconventional asset. For expository purposes, I will relegate most of the algebra to the appendix and focus primarily on the results.

\subsection{Cross-Transmission Only}

If it is assumed that cross-transmission (i.e. creditor-to-bank and bank-to-creditor) is the only channel for persuading intermediaries and investors to switch to the unconventional asset, then the following assumptions are imposed on the model: 1) $\beta_{B, B}=0$, and 2) $\beta_{C, C}$ $=0$. This reduces the herd immunity condition to the following:

$$
\begin{gathered}
2>\sqrt{\frac{4 \beta_{B, C} \beta_{C, B}}{\gamma_{C}\left(\gamma_{B}+m_{B}\right)}} \\
\rightarrow \gamma_{C}\left(\gamma_{B}+m_{B}\right)>\beta_{B, C} \beta_{C, B}
\end{gathered}
$$

The above equation yields a proof for our first theorem:

Theorem 1. If $\beta_{B, B}=0$ and $\beta_{C, C}=0$, then herd immunity will hold whenever $\gamma_{C}\left(\gamma_{B}+\right.$ $\left.m_{B}\right)>\beta_{B, C} \beta_{C, B}$.

This result suggests that higher recovery and bankruptcy rates will drain the pool of unconventional creditors and banks faster. If this occurs sufficiently fast-relative to the cross-transmission rates-then the unconventional asset will never take off, since few conventional asset holders will discover it.

Next, I will consider placing additional restrictions on the parameter values. This may be helpful to do if certain parameters are inestimable; and we need to determine them by theory in order to check herd immunity.

First, we note that $1>\gamma_{C}+m_{C}$, as is shown in the proof for Theorem 2. We will use this to construct the next set of theorems. 
Theorem 2. If $\beta_{B, C}>0, \beta_{C, B}>0, \beta_{C, C}=0, \beta_{B, B}=0$, and $b^{L}(t) \geq \frac{I_{C}-\tau I_{B}}{I_{C}}$, then herd immunity is violated.

This theorem states that the unconventional asset will spread to susceptible conventional banks and creditors if 1) cross transmission is the only channel for switching to the unconventional asset, and 2) the lower bound for the return on the unconventional asset is high enough to ensure that no banks investing in it become bankrupt.

Theorem 3. If $\beta_{B, C}>1, \beta_{C, B}>1, \beta_{C, C}=0$, and $\beta_{B, B}=0$, then herd immunity is violated if $b^{H}(t) \geq 1$.

Since $\gamma_{B}+m_{B} \leq 1$ and $\gamma_{c} \leq 1$ (since it is a probability), the inequality in equation (49) will not hold if $\beta_{B, C}>1$ and $\beta_{C, B}>1$. This suggests that if the strength of crosstransmission is sufficiently large, then the unconventional asset will continue to spread, regardless of bankruptcy and recovery rates.

\subsection{No Bank-to-Bank Transmission}

With no bank-to-bank transmission, $\beta_{B, B}$ is effectively set to zero. That is, we assume that banks consider only other creditors when deciding whether or not to switch to the unconventional asset; and do not pay attention to the choices of other banks. This reduces the condition for herd immunity to the following:

$$
2>\sqrt{\left(\frac{\beta_{C, C}}{\gamma_{C}}\right)^{2}+\frac{4 \beta_{B, C} \beta_{C, B}}{\gamma_{C}\left(\gamma_{B}+m_{B}\right)}}+\frac{\beta_{C, C}}{\gamma_{C}}
$$

Some algebraic manipulation yields the following, simpler condition:

$$
\left(\gamma_{C}-\beta_{C, C}\right)\left(\gamma_{B}+m_{B}\right)>\beta_{B, C} \beta_{C, B}
$$

This provides the first theorem for the case with no bank-to-bank transmission:

Theorem 4. If $\beta_{B, B}=0$ and $\left(\gamma_{C}-\beta_{C, C}\right)\left(\gamma_{B}+m_{B}\right)>\beta_{B, C} \beta_{C, B}$, then herd immunity holds.

Next, note that $1>\left(\gamma_{B}+m_{B}\right) \geq 0$, as is shown in the appendix. Since $\beta_{B, C}>0$, $\beta_{C, B}>0$, and $\beta_{B, B}=0$, the left hand side will be smaller whenever $\beta_{C, C}>\gamma_{B}$. This yields the next three theorems. 
Theorem 5. If $\beta_{B, B}=0$ and $\gamma_{C}>\beta_{B, B}$, then herd immunity is violated if $B_{C, B}>1$ and $B_{B, C}>1$.

Theorem 6. If $\beta_{B, B}>1$ and $\beta_{B, B} \geq 1$, then herd immunity is violated.

Theorem 7. If $\beta_{B, C}>0, \beta_{C, B}>0, \beta_{C, C}=0$, and $b^{L}(t) \geq 1$, then herd immunity is violated.

\subsection{No Creditor-to-Creditor Transmission}

If there is no creditor-to-creditor transmission, then $\beta_{C, C}=0$. This reduces the condition for herd immunity to the following:

$$
\begin{gathered}
2>\sqrt{\frac{\beta_{B, B}^{2}}{\left(\gamma_{B}+m_{B}\right)^{2}}+\frac{4 \beta_{C, B} \beta_{B, C}}{\left(\gamma_{B}+m_{B}\right) \gamma_{C}}}+\frac{\beta_{B, B}}{\gamma_{B}+m_{B}} \\
\rightarrow\left(\gamma_{B}+m_{B}-\beta_{B, B}\right) \gamma_{C}>\beta_{C, B} \beta_{B, C}
\end{gathered}
$$

This expression gives us our first creditor-to-creditor theorem:

Theorem 8. If $\beta_{C, C}=0$ and $\left(\gamma_{B}+m_{B}-\beta_{B, B}\right) \gamma_{C}>\beta_{B, C} \beta_{C, B}$, then herd immunity holds.

Next, consider the conditions under which the left hand side will be nonpositive (and, thus, violate herd immunity).

Theorem 9. If $\beta_{C, C}=0$ and $\beta_{B, B}>\left(\gamma_{B}+m_{B}\right)$, then herd immunity is violated.

Theorem 10. If $\beta_{B, C}>0, \beta_{C, B}>0, \beta_{C, C}=0$, and $b^{L}(t) \geq 1$, then herd immunity is violated.

Theorem 11. If $\beta_{B, C} \beta_{C, B}>1$ and $\beta_{C, C}=0$, then herd immunity is violated.

Theorem 12. If $\beta_{B, B}>1$ and $\beta_{C, C}=0$, then herd immunity is violated.

We now have 12 theorems that can be used to place theoretical restrictions on parameters. In some cases, making a couple of weak theoretical restrictions will make it possible to check the herd immunity condition by estimating only one parameter. 


\section{Empirical Applications}

In this section, I will discuss three applications of the SIR model that involve estimating $\mathbb{R}_{0}$. In the first, I will 1) estimate a structural equation from the SIR model, 2) use the point estimates to compute $\left.\mathbb{R}_{0} ; 3\right)$ use the delta method to compute the standard error of $\mathbb{R}_{0}$; and then 4 ) perform a hypothesis test to determine whether or not the financial innovation will spread. In the second application, I will 1) estimate two separate 1-host models for a related phenomena; 2) impose theoretical restrictions; and then 3) determine whether or not herd immunity is violated in the 2-host version of the model. In the final application, I will show how estimating $\mathbb{R}_{0}$ 35-quarters after ETFs were released in the U.S. could have been used to predict their widespread popularity. In addition to this, I will demonstrate an alternative method of estimating $\mathbb{R}_{0}$ directly, rather than constructing it from $\beta$ and $\gamma$ estimates. I will conclude by discussing the robustness of herd immunity rejections.

\subsection{Detecting the Spread of a Financial Innovation}

In the first application, I consider the introduction of non-agency, non-GSE securitized debt. The purpose of this application will be to demonstrate how to make predictions about the spread of new financial innovations using the one-host SIR framework.

The dataset was constructed using three series: 1) the level of GSE-securitized debt; 2) the level of household debt; and 3) the level of non-GSE securitized debt. The series for $\mathrm{S}$ (i.e. the fraction of debt that is susceptible to private securitization) is constructed as follows:

$$
S=\frac{\text { Total Debt }- \text { GSE-Securitized Debt - Privately-Securitized Debt }}{\text { Total Debt - GSE-Securitized Debt }}
$$

For simplicity, I will assume that there is no recovery in the model. That is, financial firms that stop securitizing do not do so permanently. Instead, they simply stop securitizing for now, but remain open to the possibility in the future. This simplifies the model by allowing us to compute I (the fraction of securitizers) as follows:

$$
I_{t}=1-S_{t}
$$


This is the SIS model. Recall that we earlier started that $\mathbb{R}_{0}$ for the SIS model is identical to the one derived earlier for the one-host SIR model. We estimate the following transformation of equation (4):

$$
\begin{aligned}
& \frac{I_{t+1}-I_{t}}{I_{t}}=\beta \frac{I_{t} S_{t}}{I_{t}}-(\gamma+m+e) \frac{I_{t}}{I_{t}} \\
& \rightarrow \frac{I_{t+1}-I_{t}}{I_{t}}=\beta S_{t}-(\gamma+m+e)
\end{aligned}
$$

Notice that $\gamma+m+e$ measures the rate at which financial firms exit the securitization business for all reasons; and $\beta$ is the contact rate multiplied by the probability of becoming a securitized. That is, in each period, a financial firm scans some fraction of other financial firms to determine which products they offer. If the firm encounters a securitizer, then it also becomes a securitizer with some fixed probability. The product of these two numbers is $\beta$.

Equation (57) was estimated with IV on quarterly data from 1983-1994, using a lag of $\mathrm{S}$ as an instrument. The results are given in Table 1 . The transmission rate $(\beta=0.8522)$ was found to exceed the mortality rate $(\gamma=.7942)$, indicating that the spread of asset backed securities was highly likely. Table I also provides $R_{0}$ and its standard error.

Note that $\mathbb{R}_{0}$ was computed as $\frac{\beta}{\gamma+m+e}$, yielding 1.0730 . $\mathbb{R}_{0}$ 's standard error was then computed as follows: let $\Sigma$ represent the covariance matrix and let $\mathrm{D}=\left[\frac{1}{\gamma+m+e},-\frac{\beta}{(\gamma+m+e)^{2}}\right]$ be the row vector of partial derivatives of $R_{0}$. Then, by the delta method, the variance of $\mathbb{R}_{0}$ is $\operatorname{var}\left(\mathbb{R}_{0}\right)=D \Sigma D^{\prime}$. In this case, $S E\left(R_{0}\right)=0.0225$. Now, recall that herd immunity be violated if:

$$
\mathbb{R}_{0}>\frac{1}{S(1-P)}
$$

Since we have the standard error for $\mathbb{R}_{0}$, we can perform a hypothesis test using data on $\mathrm{S}$ to see if herd immunity is violated. If the test is performed at the end of the period (1994), then we may reject the null hypothesis with 95\% confidence. That is, in 1994, an estimate of $R_{0}$ would have provided support for the claim that private securitization was likely to spread rapidly, which is precisely what happened until the financial crisis occurred in 2007. 


\section{TABLE I}

\section{Asset-Backed Securities Regression}

\begin{tabular}{ll}
\hline \hline$\beta$ & ABS \\
\hline & $0.8522^{* *}$ \\
& $(0.4207)$ \\
$\gamma+\mathrm{m}+\mathrm{e}$ & $0.7942^{* *}$ \\
& $(0.4079)$ \\
$R_{0}$ & $1.0730^{* * *}$ \\
& $(0.0225)$ \\
\hline Robust SE & $\mathrm{Y}$ \\
\hline $\mathrm{N}$ & 47 \\
$R^{2}$ & 0.34 \\
\hline \hline
\end{tabular}

$* * *, * *, *$ represent $1 \%, 5 \%$, and $10 \%$ statistical significance, respectively.

In practice, we could use new data to update $S, P$, and $\mathbb{R}_{0}$ in each period; and then check whether or not herd immunity holds. If herd immunity does not hold, then it may make sense to monitor the financial instrument carefully, as it could play an increasingly important role in the financial system. Alternatively, if herd immunity holds, this could suggest that the spread of the instrument will cease in the future.

From a policy perspective, we might consider adjusting P. That is, policy-makers might consider restricting securitization if they worry that a risky and untested financial instrument is likely to spread rapidly (i.e. has a high $\mathbb{R}_{0}$ ). They could achieve this by placing temporary legal limits on the issuance of the security until we have a longer period of time to evaluate its performance. Alternatively, we may adjust $\gamma$ through an intervention to reduce $\mathbb{R}_{0}$.

Finally, notice that we ignored the returns to privately-issued asset backed securities when we performed this analysis, even though this is likely to play an important role in determining entry and exit. Now, recall that $\mathbb{R}_{0}=\frac{\beta}{F(1 ; t)+e}$. This suggests that a reduction in the probability of a loss will increase $\mathbb{R}_{0}$ by reducing the outflow of unconventional 
asset holders. We can use this to determine how counterfactual scenarios will affect $\mathbb{R}_{0}$. In the next section, we will consider an example that explicitly uses the theory developed earlier to guide estimation.

\subsection{Checking the Susceptibility of FDIC-Insured Banks to a Zombie Invasion}

To illustrate the generality of this approach, we consider an example where financial innovation refers to managerial practices. Here, we consider how a change in lending and borrowing practices in a small subset of banks may spread; and incur potentially serious consequences.

The motivation for this example comes from the S\&L Crisis of the 1980s and 1990s, where many savings and loan institutions became insolvent, but were able to continue operating because of implicit and explicit government guarantees, such as deposit insurance. Kane (1987) coined the phrase "zombie bank" to describe such institutions, which were effectively dead, but were able to continue to lend and to collect deposits.

Kane (1987) points out that zombie institutions were particularly worrisome because they were tempted to "gamble for resurrection." That is, knowing that equity holders would get wiped out by an asset revaluation with certainty, they would find ways to attract creditors (e.g. by offering higher interest rates); and then invest the new funds in increasingly risky projects. If the bank was lucky and the investments paid off, then the institution would not be insolvent at revaluation, saving the equity-holders. If, on the other hand, the investments did poorly, then the new creditors would effectively subsidize the equity holders by bearing some of the losses.

The behavior of zombies is problematic for two reasons. First, it causes zombified institutions to lend to increasingly risky borrowers. And second, it encourages nearby institutions to do the same. If they do not, then they will not be able to compete with the rates zombie banks offer creditors (and creditors more generally), which results in a shift of deposits away from healthy institutions.

While the industry has undergone substantial reform since the S\&L crisis of the 1980s and 1990s, zombie banks still exist; and still have the bad incentives that come from implicit and explicit government guarantees. In a recent paper, Zwick (2012) describes a strategy for identifying zombie banks in FDIC data; and uses it to examine their impact 
on the Great Recession. ${ }^{8}$

I follow Zwick's zombie-detection approach by constructing an unbalanced panel out of 12 years (2001-2012) worth of institution-level cross-sections from the FDIC's call reports. I then use the FDIC certificate from the call reports to match the institutions to the ones listed in CalculatedRisk's unofficial record of Prompt Corrective Actions (PCA) and Desist orders. The combined dataset allows me to identify banks by location (state and county), balance sheet data, and zombie status (i.e. if they were given an order). It also permits me to link banks across time.

From there, I construct the model variables, S and I. Initially, I assume that all banks are susceptible to zombification, and identify the institutions that are given a PCA or Desist order as infected institutions. The reason I label them as infecteds prior to the order is because this is when banks are most likely to engage in high risk behavior in an attempt to divert debt-financed funding from other institutions. Furthermore, I define the mass of infecteds, $I$, as the fraction of deposit volume held by these institutions. I then estimate the following equation with OLS to recover the transmission and mortality rates:

$$
I_{i, t+1}-I_{i, t}=\beta I_{i, t} S_{i, t}-\gamma I_{i, t}+\phi_{l}+u_{t}+\epsilon_{i, t}
$$

Note that $\phi_{l}$ is a county fixed effect and $u_{t}$ is a time effect. The fixed effects will allow us to sweep out any variation that is attributable to county-specific idiosyncrasies and is unrelated to the interaction between zombies and non-zombies. The time effects will sweep out the effect of national trends, such as expansions and recessions that might create a common time trend in the fraction of deposits held by zombies.

The results are given in Table II. Notice that there are separate regressions in this table: one for the fraction of deposit volume held by zombies and another for the fraction of asset volume held by zombies within a county. The purpose behind this is to test whether zombie banks create a pure deposit-diversion epidemic or whether zombie behavior also has a substantial impact on assets.

The results suggest that there is evidence for strong deposit-side transmission at the county level. Additionally, the relative rates of transmission and mortality of infecteds suggests that deposit-side zombification (i.e. diversion of deposits away from healthy

\footnotetext{
${ }^{8}$ It is important to note that Zwick (2012) is more concerned with the "evergreening" phenomena that is described by Caballero (2008), rather than risky lending. In fact, his paper suggests that banks may tend to repeatedly rollover loans, rather than originating new, risky loans.
} 
banks) may occur if some shock introduces a small number of zombies initially. In particular, recall that a county will not have herd immunity if the following holds:

$$
\mathbb{R}_{0}>\frac{1}{S(1-P)}
$$

\section{TABLE II}

County-Level Regression Results for Zombie Banks

\begin{tabular}{lll}
\hline \hline$\beta$ & Deposits & Assets \\
\hline$\gamma+\mathrm{m}+\mathrm{e}$ & $0.3036^{* *}$ & 0.1022 \\
& $(0.0684)$ & $(0.0709)$ \\
& $0.2512^{* *}$ & $0.2211^{* *}$ \\
$R_{0}$ & $(0.0313)$ & $(0.0307)$ \\
& $1.2087^{* *}$ & $0.4623^{* *}$ \\
\hline County FE & $(0.0825)$ & $(0.1077)$ \\
Time FE & $\mathrm{Y}$ & $\mathrm{Y}$ \\
Robust SE & $\mathrm{Y}$ & $\mathrm{Y}$ \\
\hline N & 7131 & $\mathrm{Y}$ \\
$R^{2}$ & 0.25 & 7131 \\
\hline \hline
\end{tabular}

$* * *, * *, *$ represent $1 \%, 5 \%$, and $10 \%$ statistical significance, respectively.

$\mathbb{R}_{0}$ is given in Table 2 , and was constructed from $\beta$ and $\gamma$, which were recovered from the regression. For deposits, $\mathbb{R}_{0}=1.2087$ with a standard error of 0.0825 , which was calculated using the delta method. This implies that a county will lose herd immunity with $95 \%$ confidence if $S(1-P)>.8183$. That is, if a county initially has no zombies $S=1$, but then a financial shock hits and causes an institution to have negative net worth (i.e. become a zombie), then that institution will tend continue to divert deposits away from healthy institutions and convert healthy institutions into zombies. A regulator 
may intervene by increasing $\mathrm{P}$ (i.e. limiting which banks may innovate) or adjusting $\gamma$ (i.e. intervening in zombie institutions faster) to change $\mathbb{R}_{0}$.

It is important to note that the "epidemic" described is with respect to volume of assets being held by zombies, rather than the proportion of institutions that are zombies. It is entirely possible, for instance, that measures targeted at regulating non-zombies more thoroughly (i.e. increasing P) could increase the deposit flow volume to zombies, which would not necessarily help to impose herd immunity. However, if herd immunity is achieved, then the interpretation behind the epidemic's end is simple: zombies will be identified and dismantled by regulatory agencies faster (i.e. $m$ will increase) than they are able to divert deposits, resulting in a net decrease in deposit inflow to zombie institutions.

Next, consider the results for the asset regression. Here, we can see that transmission is not particularly strong (i.e. statistically insignificantly different from zero). That is, an increase in contact between zombies and non-zombies does not lead to particularly large increases in zombie asset volume. Furthermore, the zombie mortality rate is large and statistically significant, which leads to a low $\mathbb{R}_{0}$ of .4623. In this case, a zombie-driven epidemic is simply not possible on the asset-side of bank balance sheets, even if $\mathrm{P}=0$.

With these results in mind, we may return to the theoretical model of banks and creditors to take advantage of the theorems derived earlier. Here, we have a clear mapping from the model to the data: the depositors are the creditors and the depository institutions are the banks. Using these relationships, we will test whether a joint epidemic (deposits and assets) is possible if we allow for cross-transmission-that is, allow the deposit epidemic to affect the asset epidemic.

From the asset regression in Table 2, we know that there is no statistically significant bank-to-bank transmission (i.e. $\beta_{B, B}=0$ ). This means that we can use the theorems derived in section 4.2. In particular, Theorem 7 states the following: if $\beta_{B, C}>0, \beta_{C, B}>0$, and $\beta_{B, B}=0$, and $b^{L} \geq 1$, then herd immunity does not hold. In words, this means that a county will be susceptible to an epidemic when a zombie is introduced if two conditions are met: 1) all zombie institutions in the county are receiving weakly positive excess returns; and 2) there is positive cross-transmission from financial intermediaries to investors and vice versa (even if it is very small).

Thus, while regulators may be encouraged by finding that $\beta_{B, B}=0$, the model indi- 
cates that a joint epidemic (i.e. one that affects deposits and lending) can still occur if zombies institutions are currently profitable.

\subsection{Predicting the Displacement of Existing Funds by ETFs}

As a final example, I considered the expansion of exchange-traded funds (ETFs), which were introduced in the United States in 1993, and steadily grew in popularity thereafter. I used data up to 2003 to estimate $\mathbb{R}_{0}$, compare it to the fraction of other fund volume that was susceptible to being converted into an ETF (e.g. close ETF substitutes), and then check whether or not the ETF takeoff could be predicted.

For the purposes of this exercise, I used Flow of Funds (FoF) data on financial businesses from the Federal Reserve Board of Governors' data download program. I computed the total volume of funds susceptible to ETF conversion by adding up the volumes for all assets in the same category as ETFs. This included several varieties of money market mutual funds, mutual funds, and closed-end funds-all predecessors to ETFs and also likely substitute investment vehicles.

I then used the total volume of funds to compute $\mathrm{S}$ and I. S was defined as the fraction of asset volume that was concentrated in non-ETFs. And I was defined as the fraction of total asset volume concentrated in ETFs. With these definitions in place, I used 35 quarters of data to recover an early estimate of the basic reproductive ratio and then used the delta method to compute its standard error. I found that $\mathbb{R}_{0}=1.0949$ with a standard error of 0.0262 . When $R_{0}$ was computed, the fraction of susceptible funds (0.9817) was greater than $\frac{1}{\mathbb{R}_{0}}$, which suggests that herd immunity was already violated and an invasion was likely. The column labelled "indirect estimate" in Table III provides the results for this section.

It is important to note that the model's parameters are likely to evolve over time. In particular, the theoretical model implies that a change the returns distribution for ETFs will shift $\gamma$. It is also reasonable to assume that the transmission rate or exit rate may change if we consider a sufficiently long horizon. For these reasons (and also to improve precision), it may make sense to update $R_{0}$ and its error bounds when new data becomes available. Figure IV provides an updated estimate of $R_{0}$ and its $95 \%$ confidence interval from 2004 to 2012. 
TABLE III

Exchange-Traded Fund Regressions (1994-2003)

\begin{tabular}{lll}
\hline \hline & Indirect Estimate & Direct Estimate \\
\hline$R_{0}$ & $1.0949^{* * *}$ & $1.0664^{* * *}$ \\
& $(0.0262)$ & $(0.0120)$ \\
\hline Robust SE & $\mathrm{Y}$ & $\mathrm{Y}$ \\
\hline $\mathrm{N}$ & 35 & 35 \\
$R^{2}$ & .1788 & 0.99 \\
\hline \hline
\end{tabular}

$* * *, * *, *$ represent $1 \%, 5 \%$, and $10 \%$ statistical significance, respectively.

To see the usefulness of this exercise, consider Figure V, which shows the real path and three counterfactual paths for ETF share. As a regulator in 2003, we may want to predict which category of path ETFs will fall into, so that we can allocate monitoring resources appropriately. We may, for instance, want to pay careful attention to ETFs if they fall into either of the top two paths or the middle path. However, if they fall into the lower path, our limited resources might best be spent monitoring other instruments. The estimate of $\mathbb{R}_{0}$ Table III can be used to eliminate the lower paths with some probability.

Finally, note that ETFs were introduced in Europe in 1999. This means that European regulators could have used the estimate of $\mathbb{R}_{0}$ from 2003 to determine how to handle the introduction of ETFs several years after their arrival. In particular, knowing that they were likely to become a popular asset class might have encouraged regulators to handle their introduction with greater scrutiny; and to dedicate more resources to their monitoring.

\subsection{Estimating $\mathbb{R}_{0}$ Directly}

In this section, I will outline a strategy for estimating $\mathbb{R}_{0}$ directly, rather than constructing it from separate estimates of $\beta$ and $\gamma$. For convenience, we will define $\zeta=\gamma+m+e$. Next, we will rearrange the flow equation for infecteds as follows: 

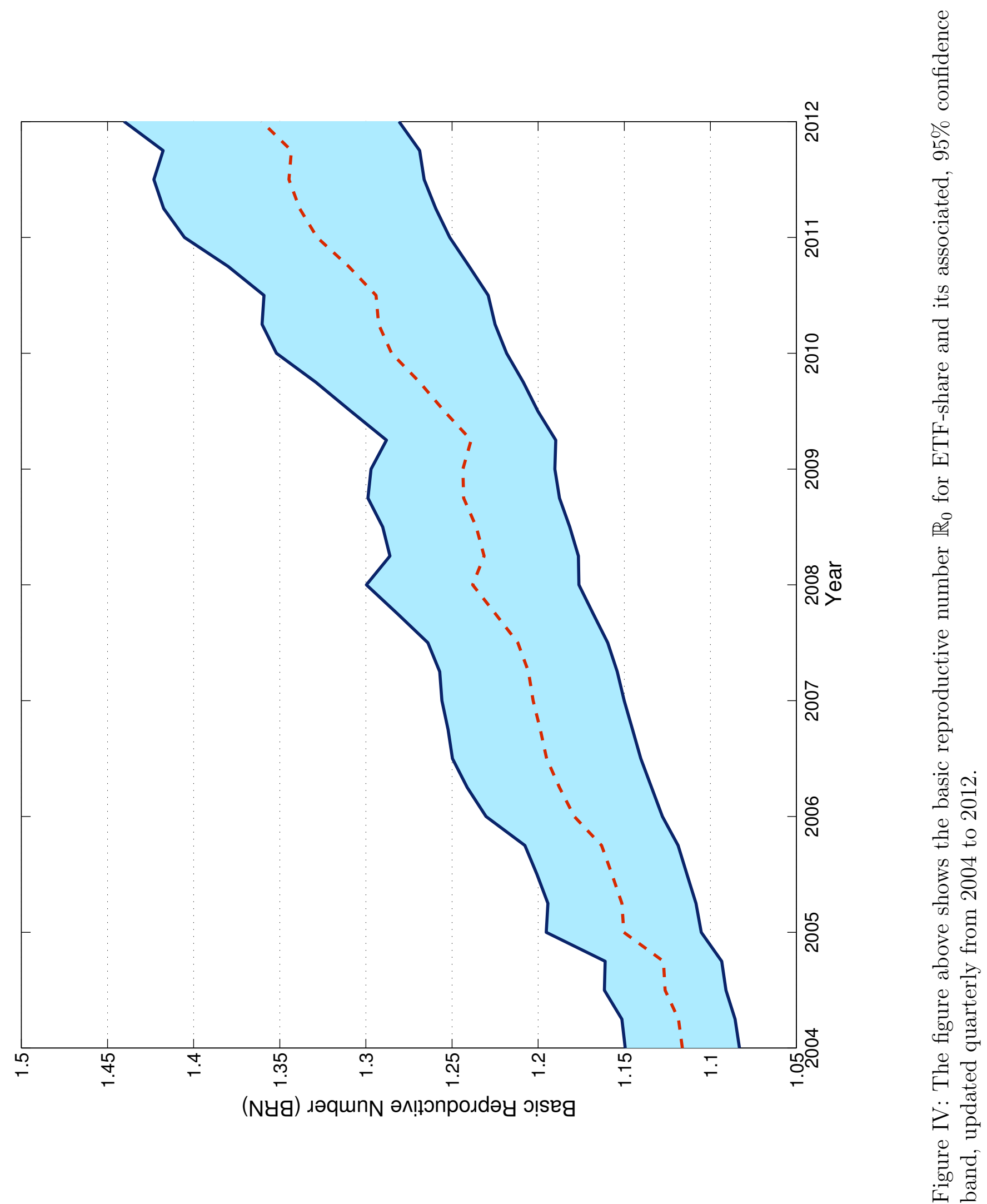


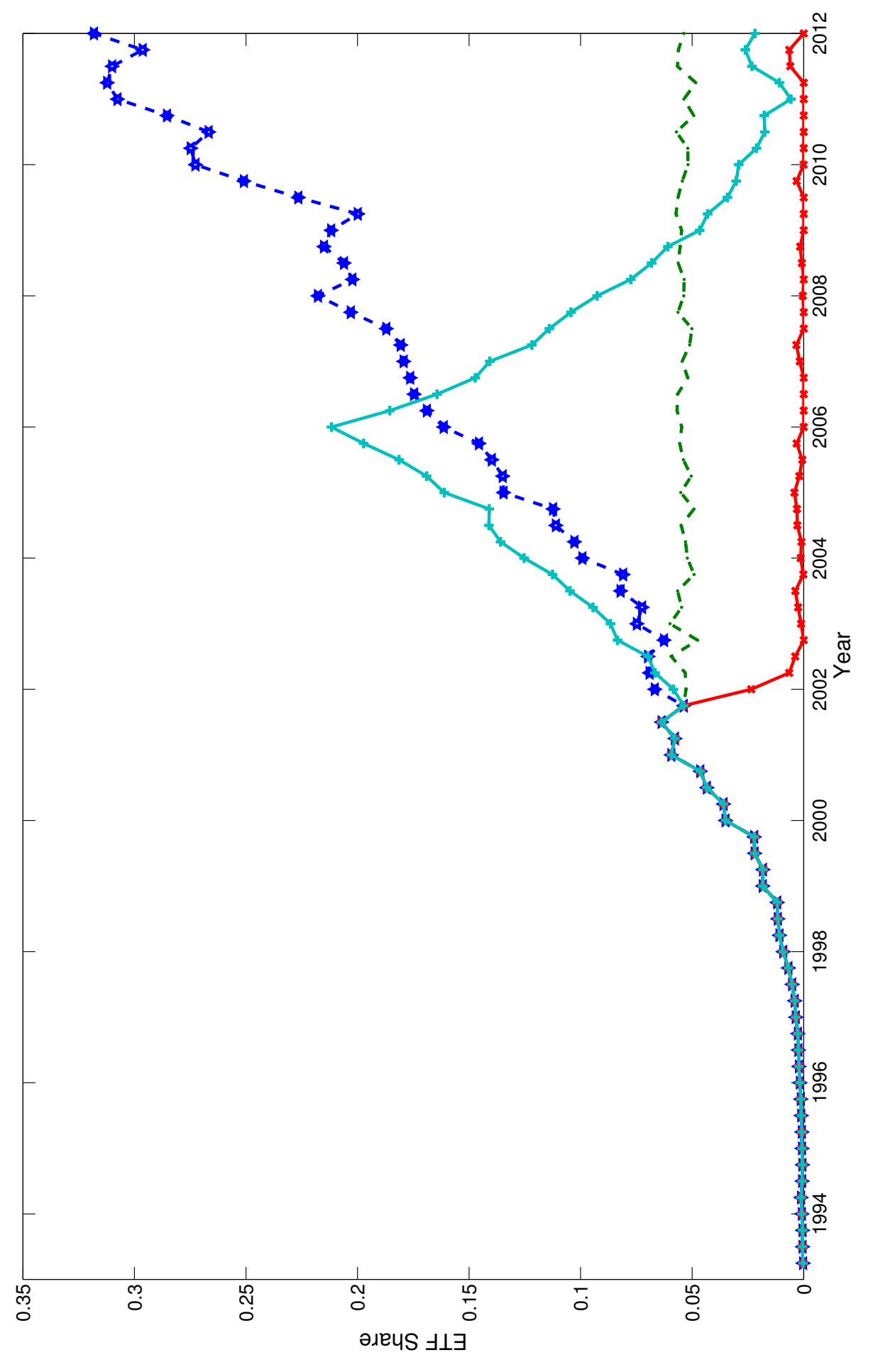

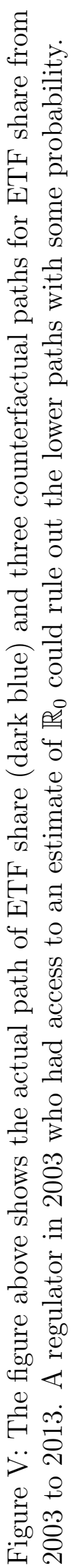




$$
I_{t+1}-I_{t}=\zeta\left(R_{0} I_{t} S_{t}-I_{t}\right)
$$

Now, assume that $I_{t} S_{t}$ and $I_{t}$ are $\mathrm{I}(1)$ processes and $I_{t+1}-I_{t}$ is an $\mathrm{I}(0)$ process. Instead of estimating the above equation, we may estimate the implied cointegration vector, $\left(\mathbb{R}_{0}, 1\right)$. In this case, the normalization choice is clear, since we wish to recover $\mathbb{R}_{0}$ directly. We may do so by estimating the following equation via OLS:

$$
I_{t}=R_{0} I_{t} S_{t}+\epsilon_{t}
$$

There are two important benefits of this approach. First, under the null hypothesis of cointegration, estimates of $\mathbb{R}_{0}$ will be superconsistent, converging at rate $\mathrm{T}$, rather than $T^{1 / 2}$. This eliminates the need for IV. The second benefit is that we do not need to compute the standard errors for $\mathbb{R}_{0}$ separately with the delta method, since $\mathbb{R}_{0}$ is estimated directly using OLS.

In order to provide a complete demonstration of this approach, I use it to repeat the estimation exercise for ETFs and to confirm the value of $\mathbb{R}_{0}$. The results are given in the "direct estimate" column of Table III. In addition to this, I also check the assumptions of the approach by performing nonstationarity tests for $I_{t}$ and $I_{t} S$, and by testing whether the two series are cointegrated under the vector $\left(\hat{\mathbb{R}}_{0}, 1\right)$.

I start by performing the following two regressions:

$$
\begin{gathered}
I_{t}=\alpha+\rho I_{t-1}+\hat{u}_{t} \\
I_{t} S=\alpha+\rho I_{t-1} S_{t-1}+\hat{u}_{t}
\end{gathered}
$$

I then use the residuals from each regression to perform two separate Phillips-Perron tests, where the null hypothesis is that the series is nonstationary. As described in Hamilton (1994), the Phillips-Perron $Z_{\rho}$ test statistic can be computed in the following set of steps:

$$
s_{C}=(T-2)^{-1} \sum_{t=1}^{T} \hat{u}_{t C}
$$




$$
\begin{gathered}
\hat{c_{j}}=(T)^{-1} \sum_{t=j+1}^{T} \hat{u_{t}} \hat{u_{t-j}} \\
\hat{\lambda}_{C}=\hat{c_{0}}+2 \sum_{j=1}^{4}[1-(j / 5)] \hat{c_{j}} \\
Z_{\rho}=T(\hat{\rho}-1)-\frac{1}{2}\left(\frac{T \hat{\sigma_{\rho}}}{s}\right)_{C}\left(\hat{\lambda_{C}}-\hat{c_{0}}\right)
\end{gathered}
$$

The test statistic, $Z_{\rho}$, is then compared to the relevant $5 \%$ critical value, which is approximately -13 for $\mathrm{T}=35$ and $\mathrm{K}=2$. For equation $(63), Z_{\rho}=1.4453>-13$, which means we fail to reject the null of nonstationarity. For equation (64), $Z_{\rho}=1.3041>-13$, which again means we fail to reject the null hypothesis of nonstationarity.

Next, equation (62) can be estimated using OLS to recover $\hat{\mathbb{R}}_{0}$. Here, I find that $\hat{\mathbb{R}}_{0}=1.0697$, which is close to the previous subsection's estimate of 1.0949 . With $\hat{\mathbb{R}}_{0}$ recovered, the cointegration of $I_{t} S$ and $I_{t}$ can be tested next. To do this, I first compute the series, z, using $\hat{\mathbb{R}}_{0}$ :

$$
z_{t}=\hat{\mathbb{R}}_{0} I_{t} S-I_{t}
$$

Next, I perform a Phillips-Perron test using the residual from the following regression:

$$
z_{t}=\alpha+\rho z_{t-1}+\hat{u}_{t}
$$

The null hypothesis is that the cointegrating relationship does not hold. For equation (53), $Z_{\rho}=-18.1478<-13$, which means we may reject the null hypothesis of no cointegration. Combined with our earlier findings, this suggests that the estimate of $\mathbb{R}_{0}$ is superconsistent.

It is important to note that there are alternative approaches to estimating $\mathbb{R}_{0}$ that may have better statistical properties in certain circumstances. However, if $I_{t}$ and $I_{t} S_{t}$ are cointegrated, then recovering $\mathbb{R}_{0}$ becomes simple. All a practitioner must do is define the three groups (S, I, and possibly R), transform the data to match the group definitions, and then estimate equation (65). If there is any doubt about the underlying assumptions needed for superconsistency, then the set of tests performed in this subsection can be employed. 


\subsection{Robustness of Herd Immunity Rejections}

In many applications, it will be unclear whether there is a "recovered" group; and, if so, whether it is identified in the data. Instead, as in this paper, there will be a mass of infecteds (I), who are holding the unconventional asset; and a mass of susceptibles, who are holding the conventional asset or whose mass is defined as 1-I for convenience. However, it may be the case that many apparent "susceptibles" held the unconventional asset at some point, experienced a negative realization from the returns distribution, and then switched back to the conventional asset. These individuals should actually be in the recovered group $(\mathrm{R})$, but this cannot be identified using the data available. An econometrician will run the following regression to recover $\beta$ and $m+\gamma$, so that $R_{0}$ can be constructed:

$$
\frac{I_{t+1}-I_{t}}{I_{t}}=-(m+\gamma)+\beta \tilde{S}_{t}+\epsilon_{t}
$$

In the above equation, the mass of susceptibles will be mismeasured if the model is, in fact, an SIR model, rather than an SIS model, since $S$ and $R$ cannot be separated:

$$
\tilde{S}_{t}=S_{t}+R_{t}
$$

This will lead to attenuation bias in $\beta$, which will also attenuate $\mathbb{R}_{0}=\frac{\beta}{m+\gamma}$. This suggests that omitting the recovered group will tend to understate the contagiousness of a security. That is, it will increase the frequency of incorrect acceptances of the herd immunity condition, but it will not cause more frequent, incorrect rejections of the herd immunity condition. This means that a regulator can be confident that a large estimate of $\mathbb{R}_{0}$ does indicate that a security is likely to become influential, but should be cautious in interpreting a small estimate of $\mathbb{R}_{0}$.

\subsection{Monte Carlo Simulation Results}

One of the two estimation strategies I described performs a regression with a stationary dependent variable $(\% \Delta I)$ and a bounded, but not covariance stationary regressor $(\mathrm{S})$. In this subsection, I will show that estimates of $\beta, \gamma+m+e$, and $\mathbb{R}_{0}$ are accurate accurate in this setting, even when only a small number of observations are available and the regressor is trending upward. 
In particular, I set $\beta=1.1, \gamma=0.95$, and $e=0.05$, which implies that $\beta=1.1$. I then simulated the SIS model for 35 periods with an initial state of $(\mathrm{S}, \mathrm{I})=(0.99,0.01)$. In each period, a random, normally distributed innovation with a standard deviation of 0.005 was drawn, and is added to I. Using the simulation results and the approach explained in the ABS application, I estimated equation (57), which yielded the results in Table IV:

TABLE IV

\section{Monte Carlo Results}

\begin{tabular}{ll}
\hline \hline & ABS \\
\hline$\beta$ & $0.9930^{* * *}$ \\
& $(0.0063)$ \\
$\gamma+\mathrm{m}+\mathrm{e}$ & $0.4960^{* * *}$ \\
& $(0.0041)$ \\
$R_{0}$ & $1.0997^{* * *}$ \\
& $(0.0056)$ \\
\hline Robust SE & $\mathrm{Y}$ \\
\hline $\mathrm{N}$ & 35 \\
$R^{2}$ & 0.99 \\
\hline \hline
\end{tabular}

$* * *, * *, *$ represent $1 \%, 5 \%$, and $10 \%$ statistical significance, respectively.

This suggests that $\mathbb{R}_{0}$ can be accurately estimated shortly after the introduction of a new financial innovation with the method outlined in the ABS section.

\section{Conclusion}

The 2007-2010 crisis was characterized by a profusion of financial innovations that neither regulators nor financial institutions fully understood. Subprime mortgages, collateralized debt obligations, and credit default swaps infiltrated the financial system to become systemically important. Both in this case and in general, regulators are generally unable to predict that new securities or managerial processes will become important or influential in advance. This limits the scope for preventative or proactive policy. An "early warning system" could remove such limitations by alerting regulators to financial 
innovations that are likely to become systemically important. Even if such a system could not discriminate between productive and unproductive innovations, it could point regulators in the direction of the systemically interesting ones, so that greater scrutiny could be applied.

This paper attempts to construct such an "early warning system" for financial innovationsbroadly defined-using a well-developed toolset from mathematical epidemiology. My approach exploits the inherently social behavior that emerges when little information is available about new securities or managerial processes. Instead of analyzing historical returns, potential early adopters examine the behavior and outcomes of the current cohort of competitors and their clients to infer the properties of an innovation. This results in dynamics akin to those in a model of infectious disease.

I focus primarily on the construction of an analog to $\mathbb{R}_{0}$ and the associated condition for herd immunity in a financial context. I show that these tools can be used to predict whether a financial innovation will become influential within the financial system or at least within its asset class. In addition to this, I demonstrate two simple strategies through which $\mathbb{R}_{0}$ can be estimated on either time series or panel data. I also evaluate the econometric robustness of the techniques, as well as the robustness of herd immunity checks to model selection.

In addition to this, I extend the model by introducing a modified version of the twohost SIR and SIS models to the economics literature. I show how this approach can be used to capture the richness of interactions between banks and their creditors; and also demonstrate how $\mathbb{R}_{0}$ and the associated herd immunity condition can be estimated and evaluated in this context.

Finally, I evaluate the approach in three separate empirical applications. I show that violations of the herd immunity condition predicted the take off of exchange traded funds (ETFs) and asset-backed securities (ABS). I also demonstrate how an estimate of $\mathbb{R}_{0}$ at the county-level can be used to evaluate whether banks in a given county are susceptible to a joint solvency crisis. I also demonstrate how policy can be used to lower the probability of a zombie financial institution invasion within a particular geographic region. 


\section{$7 \quad$ References}

Carroll, C. 2003. "Macroeconomic Expectations Of Households And Professional Forecasters." The Quarterly Journal of Economics Vol. 118(1), 269-298.

Diekmann, O. \& Heesterbeek, J.A.P. 1990. "On the Definition and the Computation of the Basic Reproduction Ratio R0 in Models for Infectious Diseases in Heterogenous Populations," Journal of Mathematical Biology Vol. 28, 365382.

van den Driessche, P. \& Watmouth, J. 2002. "Reproduction Numbers and Sub-Threshold Endemic Equilibria for Compartmental Models of Disease Transmission." Mathematical Biosciences Vol. 180, 29-48.

Feng, L. \& Seasholes, M.S. 2004. "Correlated Trading and Location. Journal of Finance Vol. 59, 21172144.

Hamilton, J. 1994. "Time Series Analysis." Princeton, NJ: Princeton University Press.

Hong, H., Kubik, J.D., \& Stein, J.C. 2004. "Social Interactions and Stock Market Participation. Journal of Finance Vol. 59, 137-163.

Hong, H., Kubik, J.D., \& Stein, J.C. 2005. "Thy Neighbors Portfolio: Word-of-Mouth Effects in the Holdings and Trades of Money Managers. Journal of Finance Vol. 60, 28012824 .

Hong, D., Hong, H., \& Ungureanu, A. 2010. "An Epidemiological Approach to Opinion and Price-Volume Dynamics." AFA 2012 Chicago Meetings Paper, Available at SSRN: http://ssrn.com/abstract=1569418 or http://dx.doi.org/10.2139/ssrn.1569418.

Ivkovic, Z. \& Weisbenner, S. 2007. "Information Diffusion Effects in Individual Investors Common Stock Purchase: Cover the Neighbors Investment Choices." Review of Financial Studies Vol. 20, 1327-1357. 
Kane, E. 1978. "Dangers of Capital Forebearance: The Case of the FSLIC and 'Zombie' S\&Ls." Contemporary Economic Policy Vol. 5(1), 77-83.

Keeling, M. \& Rohani, P. 2008. Modeling Infectious Diseases in Humans and Animals, Princeton, NJ: Princeton University Press.

Mukandavire, Z., Smith, D., \& Morris, G. 2013. "Cholera in Haiti: Reproductive Numbers and Vaccination Coverage Estimates." Scientific Reports, Vol. 3(997), 1-8.

McCormack, R. 2007. "Multi-Host and Multi-Patch Mathematical Epidemic Models for Disease Emergence with Applications to Hantavirus in Wild Rodents." Texas Tech University Dissertation in Mathematics.

Pfajfar, D. \& Santoro, E. 2012. "News on Inflation and the Epidemiology of Inflation Expectations." Discussion Paper 2012-048, Tilburg University, Center for Economic Research.

Shiller, R. \& Pound, J. 1989. "Survey Evidence on Diffusion of Interest and Information Among Investors." Journal of Economic Behavior and Organization Vol. 12, 47-66.

Shive, S. 2010. "An Epidemic Model of Investor Behavior." Journal of Financial and Quantitative Analysis Vol. 45(1), 169-198.

Sommer, M. \& Carroll, C. 2004. "Epidemiological Expectations and Consumption Dynamics." Money Macro and Finance (MMF) Research Group Conference 2003 92, Money Macro and Finance Research Group.

Zwick, E. 2012. "Regulators vs. Zombies: Loss Overhang and Lending in a Long Slump." Harvard FAS Working Paper. 


\section{Appendix}

\subsection{Proof: Theorem 1}

We start with condition for herd immunity:

$$
2>\sqrt{\left(\frac{\beta_{B, B}}{\gamma_{B}+m_{B}}-\frac{\beta_{C, C}}{\gamma_{C}}\right)^{2}+\frac{4 \beta_{B, C} \beta_{C, B}}{\left(\gamma_{B}+m_{B}\right) \gamma_{C}}}+\left(\frac{\beta_{B, B}}{\gamma_{B}+m_{B}}+\frac{\beta_{C, C}}{\gamma_{C}}\right)
$$

Next, we impose that $\beta_{B, B}=0$ and $\beta_{C, C}=0$-that is, we have cross-transmission only.

This gives us the following, simplified condition for herd immunity:

$$
\begin{gathered}
2>\sqrt{\frac{4 \beta_{B, C} \beta_{C, B}}{\left(\gamma_{B}+m_{B}\right) \gamma_{C}}} \\
\rightarrow 4>\frac{4 \beta_{B, C} \beta_{C, B}}{\left(\gamma_{B}+m_{B}\right) \gamma_{C}} \\
\rightarrow\left(\gamma_{B}+m_{B}\right) \gamma_{C}>\beta_{B, C} \beta_{C, B}
\end{gathered}
$$

\subsection{Proof: Theorem 2}

As in Theorem 1, we assume cross-transmission only. However we add to this three more assumptions: 1) $\left.\beta_{B, C}>0,2\right) \beta_{C, B}>0$, and 3) $b^{L}(t)>\frac{I_{C}-\tau I_{B}}{I_{C}}$. From here, we may skip to the final equation in the proof of Theorem 1:

$$
\rightarrow\left(\gamma_{B}+m_{B}\right) \gamma_{C}>\beta_{B, C} \beta_{C, B}
$$

Now, recall that $\beta_{B, C}>0$ and $\beta_{C, B}>0$, which implies the following:

$$
\beta_{B, C} \beta_{C, B}>0
$$

Thus, showing $0 \geq\left(\gamma_{B}+m_{B}\right) \gamma_{C}$ will be sufficient to demonstrate that herd immunity is violated. This will occur whenever $\gamma_{C}=0$, where $\gamma_{C}$ is defined as follows:

$$
\gamma_{C}=p r\left\{b(t, i)<\frac{I_{C}-\tau I_{B}}{I_{C}}\right\}
$$


Since $b^{L}(t, i) \geq \frac{I_{C}-\tau I_{B}}{I_{C}} \forall i$, no banks will realize a return that causes them to exit:

$$
\bar{b}(t, i) \geq \frac{I_{C}-\tau I_{B}}{I_{C}}
$$

This is equivalent to $\gamma_{C}=0$. Thus, herd immunity is violated:

$$
\beta_{B, C} \beta_{C, B}>0>\left(\gamma_{B}+m_{B}\right) \gamma_{C}
$$

\subsection{Proof: Theorem 3}

Again, we assume that cross-transmission is the only channel that causes creditors and banks to switch to the unconventional asset. This allows us to start with the simplified condition for herd immunity:

$$
\left(\gamma_{B}+m_{B}\right) \gamma_{C}>\beta_{B, C} \beta_{C, B}
$$

Now, we assume that $\beta_{B, C} \beta_{C, B}>1$. Since $\gamma_{C}$ is a probability, it will be weakly less than

1. Thus, if $\gamma_{B}+m_{B} \leq 1$, then herd immunity will not hold. We know that:

$$
\begin{gathered}
m_{B}=F\left(\left(I_{C}-\tau I_{B}\right) / I_{C} ; t\right) \\
\gamma_{B}=F(1 ; t)-F\left(\left(I_{C}-\tau I_{B}\right) / I_{C} ; t\right) \\
\rightarrow \gamma_{B}+m_{b}=F(1 ; t)
\end{gathered}
$$

Since $\beta_{B, C} \beta_{C, B}>1$ and $F(1 ; t) \leq 1$, we know that:

$$
\beta_{B, C} \beta_{C, B}>\left(\gamma_{B}+m_{B}\right) \gamma_{C}
$$

Thus, herd immunity is violated.

\subsection{Proof: Theorem 4}

We start by setting $\beta_{B, B}=0$. This gives us the following condition for herd immunity:

$$
2>\sqrt{\left(\frac{\beta_{C, C}}{\gamma_{C}}\right)^{2}+\frac{4 \beta_{B, C} \beta_{C, B}}{\left(\gamma_{B}+m_{B}\right) \gamma_{C}}}+\frac{\beta_{C, C}}{\gamma_{C}}
$$




$$
\rightarrow \frac{\left(2 \gamma_{C}-\beta_{C, C}\right)^{2}}{\left(\gamma_{C}\right)^{2}}>\left(\frac{\beta_{C, C}}{\gamma_{C}}\right)^{2}+\frac{4 \beta_{B, C} \beta_{C, B}}{\left(\gamma_{B}+m_{B}\right) \gamma_{C}}
$$

After rearranging, we may state the herd immunity condition more compactly:

$$
\left(\gamma_{C}-\beta_{C, C}\right)\left(\gamma_{B}+m_{B}\right)>\beta_{B, C} \beta_{C, B}
$$

\subsection{Proof: Theorem 5}

We start from equation (89):

$$
\left(\gamma_{C}-\beta_{C, C}\right)\left(\gamma_{B}+m_{B}\right)>\beta_{B, C} \beta_{C, B}
$$

We know that $1 \geq \gamma_{C}$, since it is a probability. Additionally, we know that $\left(\gamma_{C}-\beta_{C, C}\right) \geq$ $\left(\gamma_{C}-\beta_{C, C}\right)\left(\gamma_{B}+m_{B}\right)$. Thus,

$$
1 \geq\left(\gamma_{C}-\beta_{C, C}\right) \geq\left(\gamma_{C}-\beta_{C, C}\right)\left(\gamma_{B}+m_{B}\right)
$$

Since, $\beta_{B, C} \beta_{C, B}>1$, we know that:

$$
\beta_{B, C} \beta_{C, B}>1 \geq\left(\gamma_{C}-\beta_{C, C}\right)\left(\gamma_{B}+m_{B}\right)
$$

Thus, herd immunity is violated.

\subsection{Proof: Theorem 6}

We start from equation (89):

$$
\left(\gamma_{C}-\beta_{C, C}\right)\left(\gamma_{B}+m_{B}\right)>\beta_{B, C} \beta_{C, B}
$$

If $\beta_{C, C}>1$, the left hand side will be negative, since $\gamma_{C}$ is a probability. Since, $\beta_{B, C}>0$ and $\beta_{C, B}>0$, we know that:

$$
\beta_{B, C} \beta_{C, B}>0>\left(\gamma_{C}-\beta_{C, C}\right)\left(\gamma_{B}+m_{B}\right)
$$




\subsection{Proof: Theorem 7}

Recall the definitions for $\gamma_{C}, \gamma_{B}$, and $m_{B}$ from the proof for Theorem 2. If $b^{L}(t) \geq 1$, then $\gamma_{B}+m_{B}=0$, since $F(1 ; t)=0$ when all return realizations are higher than the conventional security. Thus, the condition for herd immunity will be violated. Note that this will also hold for the weaker condition: $b^{L}(t)>\frac{I_{C}-\tau I_{B}}{I_{C}}$. However, this condition cannot be mapped to the data as clearly.

\subsection{Proof: Theorem 8}

Theorem 8 states that if $\beta_{C, C}=0$ and $\left(\gamma_{B}+m_{B}-\beta_{B, B}\right) \gamma_{C}>\beta_{B, C} \beta_{C, B}$, then herd immunity holds. To prove this, we start with the condition for herd immunity, which we get from imposing $\beta_{C, C}=0$ :

$$
\begin{aligned}
& 2>\sqrt{\frac{\beta_{B, B}^{2}}{\left(\gamma_{B}+m_{B}\right)^{2}}+\frac{4 \beta_{C, B} \beta_{B, C}}{\left(\gamma_{B}+m_{B}\right) \gamma_{C}}}+\frac{\beta_{B, B}}{\gamma_{B}+m_{B}} \\
\rightarrow & \left(2-\frac{\beta_{B, B}}{\gamma_{B}+m_{B}}\right)^{2}>\frac{\beta_{B, B}^{2}}{\left(\gamma_{B}+m_{B}\right)^{2}}+\frac{4 \beta_{C, B} \beta_{B, C}}{\left(\gamma_{B}+m_{B}\right) \gamma_{C}}
\end{aligned}
$$

After rearranging, we may restate the condition for herd immunity more compactly:

$$
\rightarrow\left(\gamma_{B}+m_{B}-\beta_{B, B}\right) \gamma_{C}>\beta_{B, C} \beta_{C, B}
$$

\subsection{Proof: Theorem 9}

Theorem 9 claims that herd immunity will be violated if $\beta_{B, C}>0, \beta_{C, B}>0, \beta_{C, C}=0$ and $\beta_{B, B}>\left(\gamma_{B}+m_{B}\right)$. From equation (97), we can see that the left hand side will be negative, violating the condition for herd immunity.

\subsection{Proof: Theorem 10}

Theorem 10 states that if $\beta_{B, C}>0, \beta_{C, B}>0, \beta_{C, C}=0$, and $b^{L}(t) \geq 1$, then herd immunity is violated. To begin the proof, we start with the simplified condition for herd immunity:

$$
\rightarrow\left(\gamma_{B}+m_{B}-\beta_{B, B}\right) \gamma_{C}>\beta_{B, C} \beta_{C, B}
$$


Next, we use the definitions for $\gamma_{B}$ and $m_{B}$ to re-write the condition:

$$
\left(F(1 ; t)-\beta_{B, B}\right) \gamma_{C}>\beta_{C, B} \beta_{B, C}
$$

If $b^{L}(t) \geq 1$, then $F(1 ; t)=0$. This implies that:

$$
\beta_{B, C} \beta_{C, B}>0 \geq\left(F(1 ; t)-\beta_{B, B}\right) \gamma_{C}
$$

Thus, herd immunity is violated. Note that this will also hold under the weaker condition: $b^{L}(t)>\frac{I_{C}-\tau I_{B}}{I_{C}}$, since $1 \geq \frac{I_{C}-\tau I_{B}}{I_{C}}$.

\subsection{Proof: Theorem 11}

Theorem 11 states that if $\beta_{B, C} \beta_{C, B}>1$ and $\beta_{B, B}=0$, then herd immunity is violated. Again, recall the herd immunity condition from equation (98):

$$
\rightarrow\left(\gamma_{B}+m_{B}-\beta_{B, B}\right) \gamma_{C}>\beta_{B, C} \beta_{C, B}
$$

Now, if $\beta_{B, C} \beta_{C, B}>1$, then herd immunity will be violated if $1 \geq\left(\gamma_{B}+m_{B}-\beta_{B, B}\right) \gamma_{C}$. Additionally, note that $\gamma_{C}$ is a probability and $\gamma_{B}+m_{B}=F(1 ; t)$ are probabilities. Thus, we have:

$$
\rightarrow 1 \geq\left(\gamma_{B}+m_{B}\right) \geq\left(\gamma_{B}+m_{B}-\beta_{B, B}\right)
$$

However, we know that $\beta_{B, C} \beta_{C, B}>1$, which implies that:

$$
\beta_{B, C} \beta_{C, B}>\left(\gamma_{B}+m_{B}-\beta_{B, B}\right)
$$

Thus, herd immunity is violated.

\subsection{Proof: Theorem 12}

Theorem 12 states that, if $\beta_{B, B}>1$ and $\beta_{C, C}=0$, then herd immunity is violated. Again, we note that $F(1 ; t)=\gamma_{B}+m_{B}$. Since $1 \geq F(1 ; t)$, we know that:

$$
\beta_{B, C} \beta_{C, B}>0 \geq\left(\gamma_{B}+m_{B}-\beta_{B, B}\right) \gamma_{C}
$$

Thus, the condition for herd immunity is violated. 


\section{Earlier Working Papers:}

For a complete list of Working Papers published by Sveriges Riksbank, see www.riksbank.se

Estimation of an Adaptive Stock Market Model with Heterogeneous Agents

2005:177

by Henrik Amilon

Some Further Evidence on Interest-Rate Smoothing: The Role of Measurement Errors in the Output Gap

2005:178

by Mikael Apel and Per Jansson

Bayesian Estimation of an Open Economy DSGE Model with Incomplete Pass-Through

2005:179

by Malin Adolfson, Stefan Laséen, Jesper Lindé and Mattias Villani

Are Constant Interest Rate Forecasts Modest Interventions? Evidence from an Estimated Open Economy

DSGE Model of the Euro Area

by Malin Adolfson, Stefan Laséen, Jesper Lindé and Mattias Villani

Inference in Vector Autoregressive Models with an Informative Prior on the Steady State

by Mattias Villani

Bank Mergers, Competition and Liquidity

by Elena Carletti, Philipp Hartmann and Giancarlo Spagnolo

Testing Near-Rationality using Detailed Survey Data

by Michael F. Bryan and Stefan Palmqvist

Exploring Interactions between Real Activity and the Financial Stance

by Tor Jacobson, Jesper Lindé and Kasper Roszbach

Two-Sided Network Effects, Bank Interchange Fees, and the Allocation of Fixed Costs

by Mats $A$. Bergman

Trade Deficits in the Baltic States: How Long Will the Party Last?

by Rudolfs Bems and Kristian Jönsson

Real Exchange Rate and Consumption Fluctuations follwing Trade Liberalization

2005:181

by Kristian Jönsson

Modern Forecasting Models in Action: Improving Macroeconomic Analyses at Central Banks

by Malin Adolfson, Michael K. Andersson, Jesper Lindé, Mattias Villani and Anders Vredin

Bayesian Inference of General Linear Restrictions on the Cointegration Space

$2005: 182$

by Mattias Villani

Forecasting Performance of an Open Economy Dynamic Stochastic General Equilibrium Model

by Malin Adolfson, Stefan Laséen, Jesper Lindé and Mattias Villani

Forecast Combination and Model Averaging using Predictive Measures

by Jana Eklund and Sune Karlsson

Swedish Intervention and the Krona Float, 1993-2002

2005:184

by Owen F. Humpage and Javiera Ragnartz

A Simultaneous Model of the Swedish Krona, the US Dollar and the Euro

2005:185

by Hans Lindblad and Peter Sellin

Testing Theories of Job Creation: Does Supply Create Its Own Demand?

by Mikael Carlsson, Stefan Eriksson and Nils Gottfries

Down or Out: Assessing The Welfare Costs of Household Investment Mistakes

by Laurent E. Calvet, John Y. Campbell and Paolo Sodini

Efficient Bayesian Inference for Multiple Change-Point and Mixture Innovation Models

by Paolo Giordani and Robert Kohn

Derivation and Estimation of a New Keynesian Phillips Curve in a Small Open Economy

by Karolina Holmberg

Technology Shocks and the Labour-Input Response: Evidence from Firm-Level Data

2005:187

2005:188

by Mikael Carlsson and Jon Smedsaas

Monetary Policy and Staggered Wage Bargaining when Prices are Sticky

by Mikael Carlsson and Andreas Westermark

2005:189

$2005: 190$

2005:191

2006:192

The Swedish External Position and the Krona

2006:193

by Philip $R$. Lane 
Evaluating Microfoundations for Aggregate Price Rigidities: Evidence from Matched Firm-Level Data on

Monetary Policy Trade-Offs in an Estimated Open-Economy DSGE Model

by Malin Adolfson, Stefan Laséen, Jesper Lindé and Lars E. O. Svensson

Flexible Modeling of Conditional Distributions Using Smooth Mixtures of Asymmetric

Student T Densities

by Feng Li, Mattias Villani and Robert Kohn

Forecasting Macroeconomic Time Series with Locally Adaptive Signal Extraction

Risk Premiums and Macroeconomic Dynamics in a Heterogeneous Agent Model

by Ferre De Graeve, Maarten Dossche, Marina Emiris, Henri Sneessens and Raf Wouters

Picking the Brains of MPC Members

by Mikael Apel, Carl Andreas Claussen and Petra Lennartsdotter

Involuntary Unemployment and the Business Cycle

by Lawrence J. Christiano, Mathias Trabandt and Karl Walentin

Housing collateral and the monetary transmission mechanism

by Karl Walentin and Peter Sellin

The Discursive Dilemma in Monetary Policy

by Carl Andreas Claussen and Øistein Røisland

Monetary Regime Change and Business Cycles

by Luca Sala, Ulf Söderström and Antonella Trigari

Density-Conditional Forecasts in Dynamic Multivariate Models by Michael K. Andersson, Stefan Palmqvist and Daniel F. Waggoner

Anticipated Alternative Policy-Rate Paths in Policy Simulations

The Effects of Endogenuos Firm Exit on Business Cycle Dynamics and Optimal Fiscal Policy 

Sveriges Riksbank

Visiting address: Brunkebergs torg 11

Mail address: se-103 37 Stockholm

Website: www.riksbank.se

SVERIGES Telephone: +46 878700 00, Fax: +46 8210531

RIKSBANK E-mail: registratorn@riksbank.se 